\title{
Investigating six-degree-of-freedom loading of shallow foundations on sand
}

\author{
B. BIENEN*, B. W. BYRNE†, G. T. HOULSBY† and M. J. CASSIDY*
}

\begin{abstract}
Laboratory studies of the response of shallow foundations have previously considered only planar loading. This paper describes experimental work carried out using a loading device that applies general loading onto model shallow foundations. The loading, involving all six degrees of freedom [vertical $(\mathrm{V})$, horizontal $\left(\mathrm{H}_{2}, \mathrm{H}_{3}\right)$, torsion $(Q)$ and overturning moment $\left.\left(M_{2}, M_{3}\right)\right]$, has been applied to a $150 \mathrm{~mm}$ diameter circular flat rough foundation on a loose dry silica sand. Aspects of the loading rig design are briefly described, but the main focus is the presentation of the experimental results. These provide evidence for the generalisation of existing work-hardening plasticity models from planar loading to general loading conditions. This evidence is used to extend an existing numerical model to the six-degree-of-freedom case, and the simulation results are compared with the experimental results.
\end{abstract}

KEYWORDS: footings/foundations; numerical modelling and analysis; offshore engineering; sands; settlement; soil/structure interaction
Les études en laboratoire de la réponse de fondations peu profondes n'ont jusqu'ici pris en compte que la charge planaire. Cet exposé décrit les travaux expérimentaux effectués en utilisant un dispositif de charge qui applique une charge générale à deux modèles de fondations peu profondes. La charge, qui met en oeuvre les six degrés de liberté [verticale $(V)$, horizontale $\left(H_{2}, H_{3}\right)$, torsion $(Q)$ et moment de retournement $\left.\left(M_{2}, M_{3}\right)\right]$, a été appliquée à une fondation plate circulaire de $150 \mathrm{~mm}$ de diamètre dans un sable de silice sec et meuble. Nous décrivons brièvement les aspects de cette installation mais ce qui importe vraiment est la présentation des résultats expérimentaux. Ceux-ci fournissent une preuve en faveur de la généralisation des modèles existants de plasticité durcissant à froid des conditions de charge planaire sous condition de charge générale. Cette preuve est utilisée pour élargir un modèle numérique existant au cas de liberté de six degrés; les résultats de la simulation sont comparés aux résultats expérimentaux.

\section{INTRODUCTION}

Understanding the response of circular shallow foundations to general loading is an important branch of geotechnical engineering. In particular, when considering the design of the foundations for offshore structures it is important to understand the load-displacement response (that is, the stiffness) as well as the ultimate capacity. This is the case for the two offshore structures shown in Fig. 1. The first is a concept for an offshore wind turbine, and the second represents a mobile jack-up drilling unit. The severe loading conditions found offshore often lead to large vertical $(V)$, horizontal $(H)$ and moment $(M)$ loads being applied to the foundations, with typical resultant loads for the two applications shown in the figure. There are clearly differences in the magnitudes of loads applied to the structures, and the foundations must be designed to carry these loads safely. A typical assumption is that the loads applied to the structure are in-plane. However, for both of the applications shown this is clearly a simplification of the actual conditions. For instance, in the case of the wind turbine the wind and wave directions may not be collinear. Therefore the loads applied to the foundation cannot be represented as planar. Similarly, for the mobile drilling unit the environmental forces on the structure might apply torsions to the foundations as well as moment and horizontal loads that are not co-planar. Therefore, to correctly predict the response and capacity of these structures it is necessary to understand the effect that three-

Manuscript received 3 January 2006; revised manuscript accepted 25 April 2006.

Discussion on this paper closes on 1 February 2007, for further details see p. ii.

* Centre for Offshore Foundation Systems, University of Western Australia.

$\dagger$ Department of Engineering Science, University of Oxford, UK. dimensional loading conditions might have on the foundation response.

Earlier studies such as those by Meyerhof (1953), Hansen (1961, 1970) and Vesic $(1973,1975)$ considered ultimate capacity of shallow foundations under the applied in-plane loads. Foundation shape and load eccentricity were accounted for with empirical parameters. However, this approach is not appropriate for prediction of foundation stiffness and incorporation into numerical analysis packages. More recent studies (Gottardi et al., 1999; Martin \& Houlsby, 2000, 2001; Byrne \& Houlsby, 2001; Cassidy et al., 2002; Houlsby \& Cassidy, 2002) have developed an alternative framework based on the theory of strain-hardening plasticity. In these studies the theoretical development has been linked with experimental work to calibrate the models. The theories provide a very satisfactory simulation
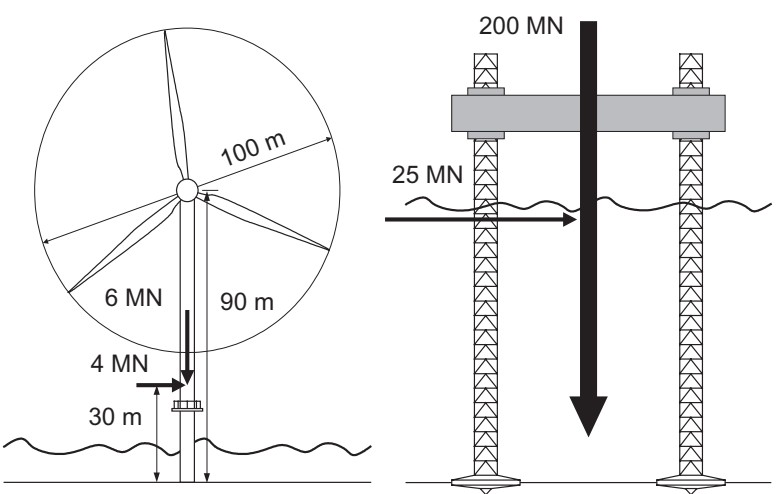

Fig. 1. Two different structures where three-dimensional effects must be accounted for 
of the load-displacement behaviour of shallow foundations, and are now being applied to other soil-structure interaction problems (such as pipelines).

For combined loading on circular foundations the theory has four components

(a) a yield surface determining the interaction between the relevant loads $(V, M / 2 R, H)$

(b) a description of the elastic behaviour of the footing for load states within the yield surface

(c) a hardening law that defines how the yield surface expands or contracts

(d) a plastic potential that describes the incremental plastic displacements at yield.

These components have been established for three-degree-offreedom loading of shallow foundations on clay (Martin \& Houlsby, 2000, 2001), dense sand (Gottardi et al., 1999; Houlsby \& Cassidy, 2002) and loose carbonate sand (Byrne \& Houlsby, 2001; Cassidy et al., 2002). The loads in the model are defined in Fig. 2(a), where the moment is converted to units of force by dividing through by $2 R$, and the rotations are converted to units of displacement by multiplying by $2 R$.

The yield surface for the planar loading problem is elliptical in the $M / 2 R: H$ plane and parabolic in the $V: H$ and $V: M / 2 R$ planes. Experimental work shows that the ratio of the horizontal to rotational loading influences the combined load capacity of the footing in the $M / 2 R: H$ plane (Gottardi \& Butterfield, 1993). Therefore the ellipse in this plane is rotated with respect to the load axes. This rotation is achieved by using a cross-coupling term and an eccentricity parameter $a$. The yield surface is given by

$$
f=\left(\frac{h}{h_{0}}\right)^{2}+\left(\frac{m}{m_{0}}\right)^{2}-2 a \frac{h}{h_{0}} \frac{m}{m_{0}}-\beta_{12} v^{2 \beta_{1}}(1-v)^{2 \beta_{2}}=0
$$

where $h=H / V_{0}, m=(M / 2 R) / V_{0}, v=V / V_{0}, h_{0}$ is the normalised horizontal load capacity, $m_{0}$ is the normalised moment capacity, $a$ is the eccentricity of the ellipse in the $h: m$ plane,

$$
\beta_{12}=\left[\frac{\left(\beta_{1}+\beta_{2}\right)^{\left(\beta_{1}+\beta_{2}\right)}}{\beta_{1}^{\beta_{1}} \beta_{2}^{\beta_{2}}}\right]^{2}
$$

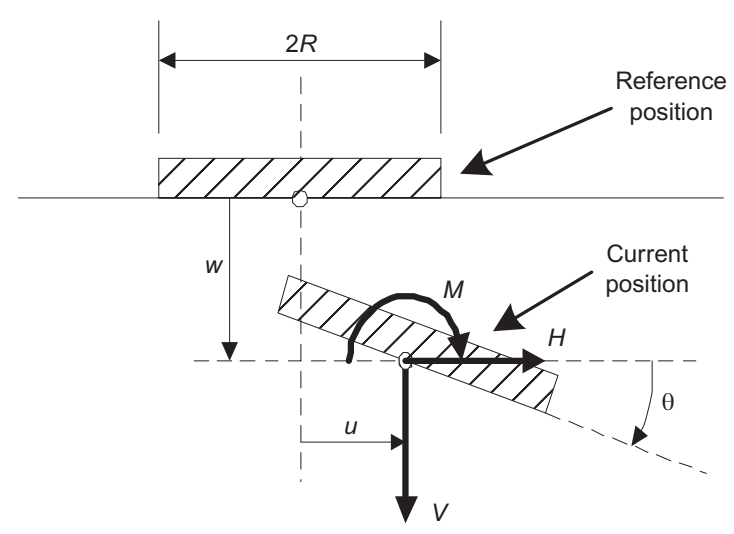

(a) and $\beta_{1}$ and $\beta_{2}$ are shaping parameters for the yield surface in the vertical load plane (Nova \& Montrasio, 1991). Studies have identified the parameter values for the yield surface for a variety of footing types and for different soils: for example, see Gottardi et al. (1999) for shallow circular foundations on dense sand, Martin \& Houlsby (2000) for spudcans on clay, or Byrne \& Houlsby (2001) for circular foundations on contracting carbonate sand.

A natural extension of these theories is to six degrees of freedom, and Martin (1994) proposed an expression for this case as follows.

$$
\begin{aligned}
f= & \left(\frac{h_{2}}{h_{0}}\right)^{2}+\left(\frac{h_{3}}{h_{0}}\right)^{2}+\left(\frac{m_{2}}{m_{0}}\right)^{2}+\left(\frac{m_{3}}{m_{0}}\right)^{2} \\
& -2 a\left(\frac{h_{3} m_{2}-h_{2} m_{3}}{h_{0} m_{0}}\right)+\left(\frac{q}{q_{0}}\right)^{2}-\beta_{12} v^{2 \beta_{1}}(1-v)^{2 \beta_{2}} \\
= & 0
\end{aligned}
$$

where $h_{2}=H_{2} / V_{0}, h_{3}=H_{3} / V_{0}, m_{2}=\left(M_{2} / 2 R\right) / V_{0}, m_{3}=$ $\left(M_{3} / 2 R\right) / V_{0}$ and $q=(Q / 2 R) / V_{0}$. The loading directions are defined in Fig. 2(b) and follow Butterfield et al. (1997). The small displacements work-conjugate to the loads $\left(\mathrm{V}, \mathrm{H}_{2}, \mathrm{H}_{3}\right.$, $\left.Q / 2 R, M_{2} / 2 R, M_{3} / 2 R\right)$ are $\left(w, u_{2}, u_{3}, 2 R \omega, 2 R \theta_{2}, 2 R \theta_{3}\right)$. When extending the yield surface formulation from three to six degrees of freedom it can be deduced from symmetry that there are no cross-coupling terms involving $\mathrm{H}_{2} \mathrm{H}_{3}$, $M_{2} M_{3}, H_{2} M_{2}, H_{3} M_{3}$ or any coupling terms including torsion $Q$ (Martin, 1994; Cassidy \& Bienen, 2002). There has, however, been no systematic study of footing response to full six-degree-of-freedom loading to verify the extension of the planar loading theories to the general case. This paper describes the development of a loading rig and the results of experimental work to verify equation (2), and then the development of a full-plasticity numerical model based on the experimental results.

\section{EQUIPMENT}

Typically, in robotics applications, the Stewart platform (Stewart, 1965) is considered to be the most elegant approach for achieving general motion of a platform. The device described in this paper is a variant of the Stewart platform (Stewart, 1965; Byrne \& Houlsby, 2005), and

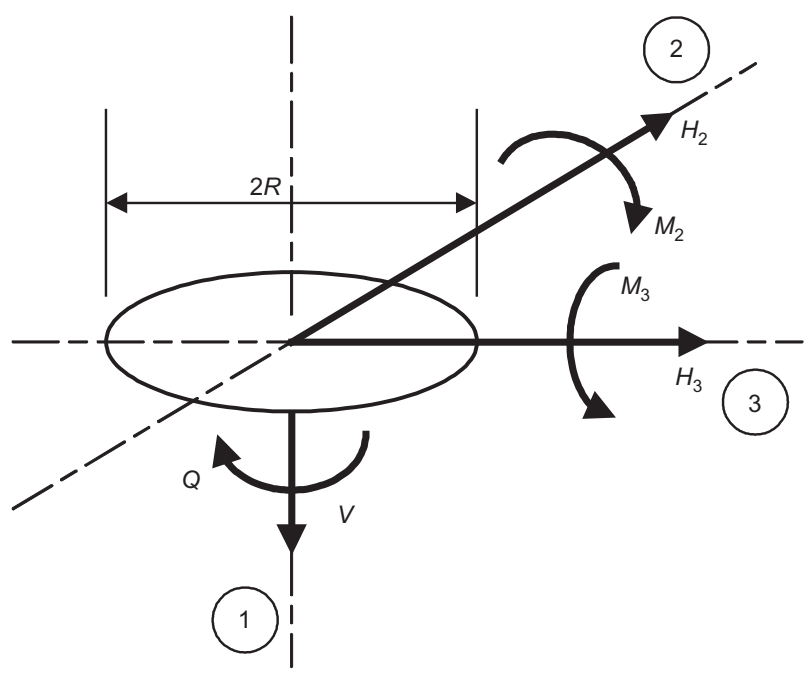

(b)

Fig. 2. Notations and conventions for a foundation under: (a) three-degree-of-freedom loading; (b) six-degree-of-freedom loading (after Butterfield et al., 1997) 
similar arrangements are used, for instance, in the automobile industry for dynamic testing of vehicles.

\section{The testing rig}

The system uses six actuators that, at one end, are connected to the loading platform, and at the other are connected to a stiff reaction frame. Provided that six properly arranged actuators are used, pinned at both ends, then it is possible to achieve six-degree-of-freedom motion of the platform by changing the lengths of the actuators in a coordinated fashion. By careful selection of the actuator geometry, it is possible to ensure that the control problem is well conditioned, so that calculations proceed in a straightforward fashion.

The disadvantage of the Stewart platform is that the simple motions are not linearly or independently related to the motion of any individual actuator, unlike the planar loading system designed by Martin (1994). Quite complex control routines are required to ensure that all actuators move in concert to achieve the desired motion. Fig. 3 shows the loading rig as constructed, showing three actuators approximately vertical and three actuators approximately horizontal. This arrangement ensures that the problem is well conditioned, as the main motions can be directly related to the motions of a subset of the actuators. For example, to achieve vertical movement the three vertical actuators must move the same distance, whereas only a slight adjustment of the horizontal actuators is required.
The actuators, supplied by Ultra Motion, are linear actuators each powered by an Animatics SmartMotor. This is a brushless DC servo-motor incorporating an integrated control system comprising a motion controller, encoder and amplifier. The actuators have a maximum extension of $200 \mathrm{~mm}$ and can move at rates of up to $5 \mathrm{~mm} / \mathrm{s}$. Commands to individual actuators can specify relative motions, position, velocity or acceleration, and they can be executed simultaneously. A number of sequential moves can be downloaded to on-board memory on the actuators, and then executed according to a synchronised clock system. This makes it possible to execute complicated platform motions provided one can determine, in advance, a time history of the individual actuator motions required.

\section{The control program}

A program has been written in Visual Basic to control the system. The program allows input of a sequence of moves in terms of the motions $\left(w, u_{2}, u_{3}, \omega, \theta_{2}, \theta_{3}\right)$ of the platform, known as the pose. These motions can be described in terms of a rotation and translation matrix (that is, a transformation matrix). By using the transformation matrix, applied to the coordinates of the platform, it is possible to determine the required lengths of each actuator for a particular move. To move the platform to the new position simply requires extending/retracting each actuator to its required length. This calculation procedure is known as the inverse kinematics problem and is a simple analytical calculation.

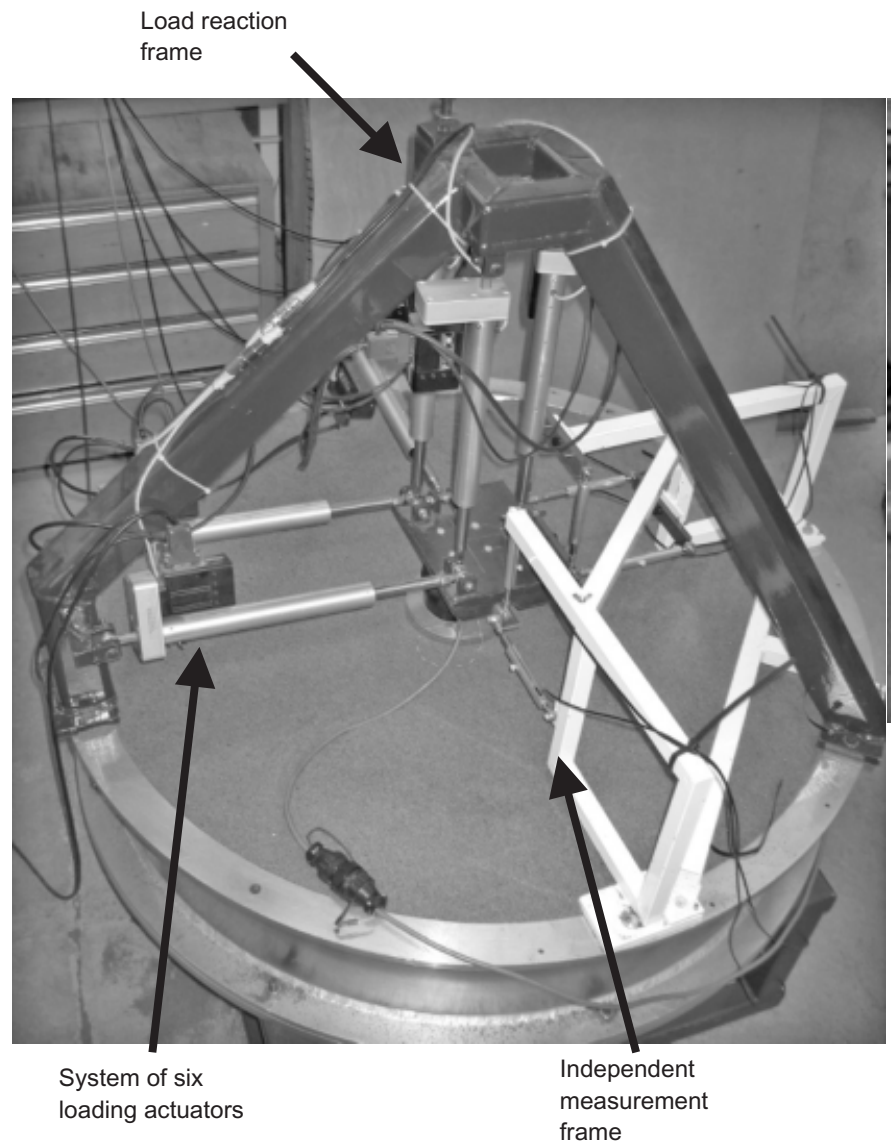

(a)

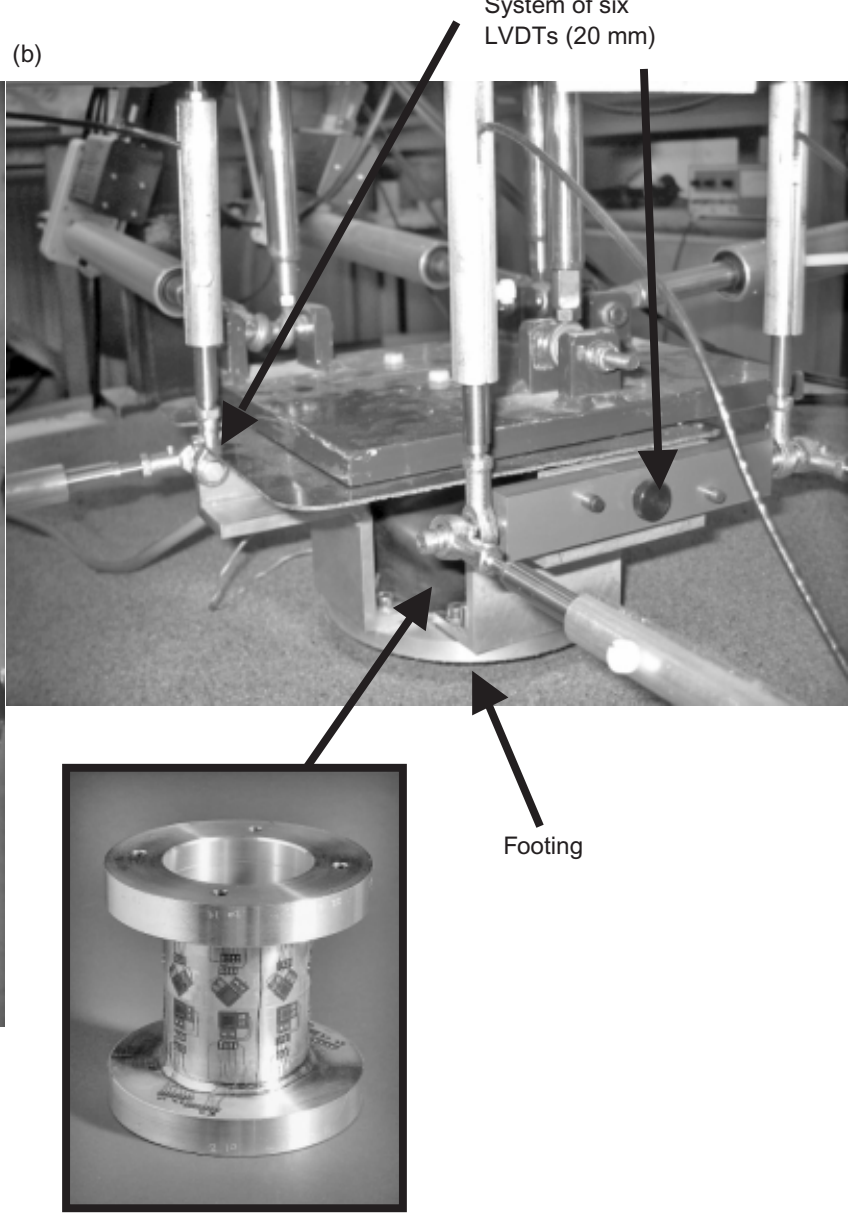

(c)

Fig. 3. Loading apparatus, showing: (a) general arrangement; (b) close-up of footing and LVDT arrangement; (c) detail of six-degreeof-freedom load cell 
The reverse calculation, called the forward kinematics problem, is not so straightforward, and requires an iterative solution. If the lengths of each actuator are known, then it is possible to calculate the new pose of the platform. Within the actuators are linear potentiometers that allow measurement of the current length of each actuator, and therefore can be used to determine the pose of the platform. Both inverse and forward kinematics procedures are performed within the software.

A typical test proceeds by determining the initial platform pose using the forward procedure. The user then specifies a sequence of moves. These moves are broken into increments so that the non-linearity of motion of each actuator can be captured. The inverse procedure is used to calculate for each of the moves the required length of each actuator. A file of actuator lengths with time (position-time data) is recorded. The relevant data from this file are sent to each actuator, and each movement is executed simultaneously. While the moves are being performed the control program logs the data. In particular, the actuator lengths are recorded and the platform pose is calculated and displayed. Currently the loading device can execute displacement-controlled motions and only relatively simple load control sub-tests. The tests described in this paper are all displacement controlled.

\section{Load cell}

The load cell measures the six components of load on the foundation, which for these tests was a rough flat circular footing $150 \mathrm{~mm}$ in diameter. The load cell is a thin-walled cylinder, fabricated from aluminium alloy, of radius $r=$ $27.5 \mathrm{~mm}$, wall thickness $t=0.475 \mathrm{~mm}$ and length $70 \mathrm{~mm}$. The thin-walled section was machined from a larger block, leaving heavy end flanges with an appropriate transition from cylinder to flanges to minimise stress concentrations. A total of 32 strain gauges are fixed to the outer surface of the cylinder to measure appropriate strains. Fig. 3(c) shows the completed cell. The strain gauges were arranged in six Wheatstone bridge circuits, each corresponding to the measurement of a particular load component. Each circuit was fully compensated for temperature. Eight gauges were used for the vertical and torque circuits, and four gauges for each of the moment and horizontal load circuits. The cell was calibrated by applying known loads and measuring the output from all six circuits. By varying the loads one at a time, it is possible to determine components of the matrix $\mathbf{X}$ relating loads to voltages in the equation $\mathbf{C}=\mathbf{X F}$, where $\mathbf{C}$ is the circuit output vector and $\mathbf{F}$ is the load vector. Inverting $\mathbf{X}$ produces a six-by-six calibration matrix, so that loads are calculated during the experiment. As the loads are calculated they need to be transformed from the local coordinate system (that is, the rotated system) back to the global system so that they are in accordance with the convention shown in Fig. 2(b).

\section{Small LVDT system}

One determination of the platform pose is achieved by using the linear potentiometers within the actuators. This, however, provides only a coarse measurement of the platform pose. In particular, the rig stiffness affects the accuracy of this measurement. To achieve more accurate displacements a system of small linear variable displacement transducers (LVDTs) (20 $\mathrm{mm}$ range) is used. These are placed in a similar configuration to that of the actuators, but supported on a separate frame, as shown in Fig. 3(a). The forward kinematics calculation is used to determine the pose of the platform, given the lengths of the LVDTs. This allows very fine resolution of the foundation movement, to the order of a few micrometres.

\section{Soil characteristics}

The experiments were carried out on dry yellow Leighton Buzzard 14/25 silica sand. The characteristics are summarised in Table 1, and further information can be found in Schnaid (1990). The sand was carefully placed into the tank to achieve a very loose state. The average density of all tests was $14.80 \mathrm{kN} / \mathrm{m}^{3}$, which corresponds to a relative density $R_{\mathrm{d}}$ of $5 \%$. An overview of all the tests completed, including details of the soil density for each test, can be found in Bienen et al. (2005).

\section{EXPERIMENTAL WORK}

The experimental programme was designed to allow verification of the theory for six-degree-of-freedom loading. Specifically, the testing concentrated on 'swipe' testing (Tan, 1990; Martin, 1994; Gottardi et al., 1999; Byrne, 2000; Martin \& Houlsby, 2000), including in-plane swipe tests, torsion swipe tests and out-of-plane loading combinations, as these have not been tested before. The swipe tests can be used to determine the shape of the yield surface. Other experiments, such as vertical loading tests and radial displacement tests, were performed to investigate the elastic response, the hardening behaviour and the flow rule. A summary of the different tests is given in Table 2. More details of the experiments and all of the data are found in Bienen et al. (2005).

\section{Yield surface}

A swipe is performed by vertically loading the footing to a prescribed value, after which the footing is translated or rotated while the vertical displacement is kept constant. The measured loads provide direct information on the shape of the yield surface for that load path. If several of these tests are carried out at different deviatoric load combinations then it is possible to fit a surface to the data, such as the one given by equation (1) for three degrees of freedom. This strategy has been successfully used for the three-degree-offreedom footing models. The same strategy can be employed for the six-degree-of-freedom expression (equation (2)), although the number of tests becomes many times greater. In six degrees of freedom the swipes include both planar loadings and out-of-plane loadings. In order to reduce the number of tests to a feasible number, careful planning of tests is required (see Table 2).

A typical series of swipe tests for horizontal translations is shown in Fig. 4. The experiments were carried out by moving the footing to a predetermined vertical displacement, locking at that displacement, and then translating the footing horizontally. Once the test is completed the footing is translated back to its original position before being penetrated further into the sand, where a further test can be carried out. Provided that sufficient vertical penetration occurs, so that the virgin penetration line is rejoined, it is assumed that the previous test history will be erased and that the footing is penetrating through virgin soil. This allows several tests to be completed on any one sample. This strategy was employed successfully by Martin (1994) and

Table 1. Soil characteristics: yellow Leighton Buzzard sand

\begin{tabular}{l|c}
\hline Particle sizes $D_{10}, D_{30}, D_{50}, D_{60}: \mathrm{mm}$ & $0 \cdot 63,0 \cdot 70,0 \cdot 80,0 \cdot 85$ \\
Specific gravity, $G_{\mathrm{s}}$ & $2 \cdot 65$ \\
Coefficient of uniformity, $C_{\mathrm{u}}$ & $1 \cdot 3$ \\
Minimum dry density, $\gamma_{\min }: \mathrm{kN} / \mathrm{m}^{3}$ & $14 \cdot 65$ \\
Maximum dry density, $\gamma_{\max }: \mathrm{kN} / \mathrm{m}^{3}$ & $17 \cdot 58$ \\
Critical state friction angle, $\phi_{\mathrm{cs}}:$ degrees & $34 \cdot 3$
\end{tabular}


Table 2. Test programme

\begin{tabular}{|c|c|c|}
\hline Test & Number & Test numbers \\
\hline $\begin{array}{l}\text { Vertical loading } \\
\mathrm{H} \text { swipe } \\
\mathrm{M} \text { swipe } \\
\text { Q swipe } \\
\text { Combined HM swipe: in plane } \\
\text { Combined HM swipe: out of plane } \\
\text { Combined HQ swipe } \\
\text { Consecutive } \mathrm{H} \text { swipes } \\
\text { Consecutive } \mathrm{M} \text { swipes } \\
\text { Consecutive } \mathrm{H} \rightarrow \mathrm{Q}(\mathrm{Q} \rightarrow \mathrm{H}) \text { swipes } \\
\text { Consecutive } \mathrm{M} \rightarrow \mathrm{Q}(\mathrm{Q} \rightarrow \mathrm{M}) \text { swipes } \\
\text { Consecutive } \mathrm{H} \rightarrow \mathrm{M}(\mathrm{M} \rightarrow \mathrm{H}) \text { swipes: in plane } \\
\text { Consecutive } \mathrm{H} \rightarrow \mathrm{M}(\mathrm{M} \rightarrow \mathrm{H}) \text { swipes: out of plane } \\
\text { Radial displacement, } \mathrm{d} \omega / \mathrm{d} z \\
\text { Radial displacement, } \mathrm{d} u / \mathrm{d} z \\
\text { Radial displacement, } \mathrm{d} \theta / \mathrm{d} z \\
\text { Combined radial displacement } \\
\text { Elasticity tests } \\
\text { Total }\end{array}$ & $\begin{array}{r}4 \\
16 \\
4 \\
10 \\
11 \\
1 \\
4 \\
9 \\
6 \\
7 \\
5 \\
4 \\
7 \\
10 \\
6 \\
3 \\
2 \\
4 \\
113\end{array}$ & $\begin{array}{c}\text { BB01, BB02, BB35, BB36 } \\
\text { BB03, BB08, BB09, BB15, BB16 } \\
\text { BB04, BB10, BB14 } \\
\text { BB11, BB17, BB32, BB33, BB35 } \\
\text { BB06, BB07, BB18, BB36, BB37, BB38, BB39 } \\
\text { BB05 } \\
\text { BB17 } \\
\text { BB12, BB13, BB19, BB33 } \\
\text { BB14, BB20 } \\
\text { BB21, BB25, BB26, BB27, BB29 } \\
\text { BB23, BB24, BB27, BB28 } \\
\text { BB22, BB30, BB31 } \\
\text { BB23, BB24, BB26, BB30, BB32 } \\
\text { BB21, BB22, BB35 } \\
\text { BB20, BB22, BB26, BB28, BB29, BB30, BB31, BB33, BB34, B } 3 \text { BB21, BB24, BB27, BB32, BB33, BB37 } \\
\text { BB23, BB25, BB38 } \\
\text { BB36, BB39 } \\
\text { BB34 }\end{array}$ \\
\hline
\end{tabular}

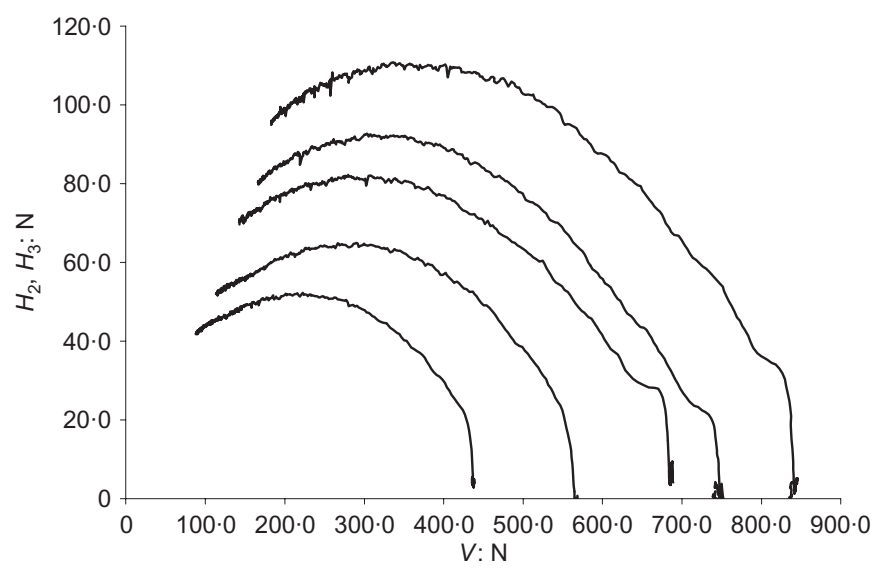

(a)

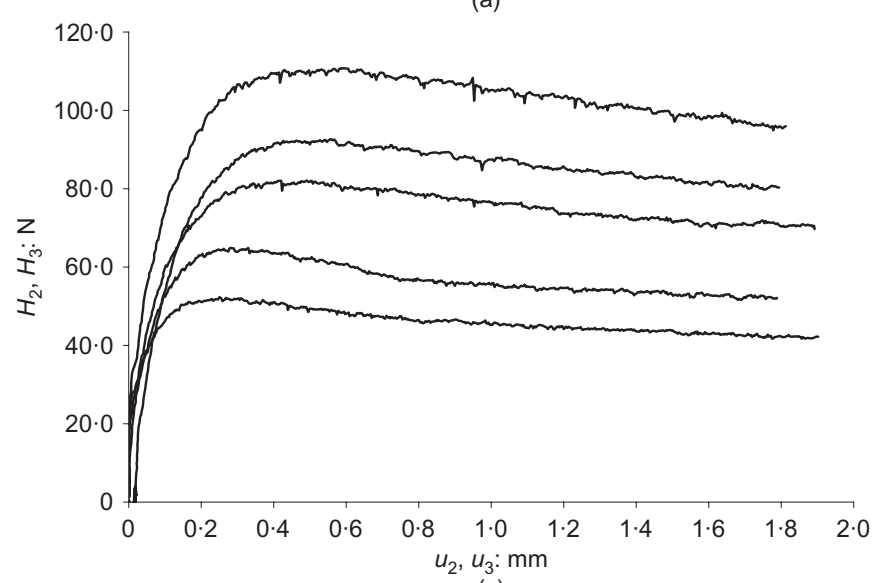

(c)

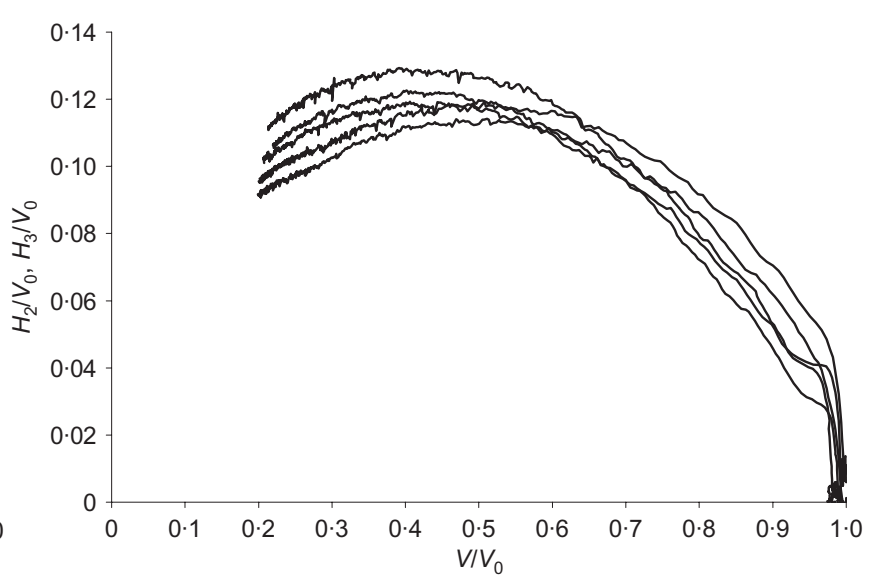

(b)

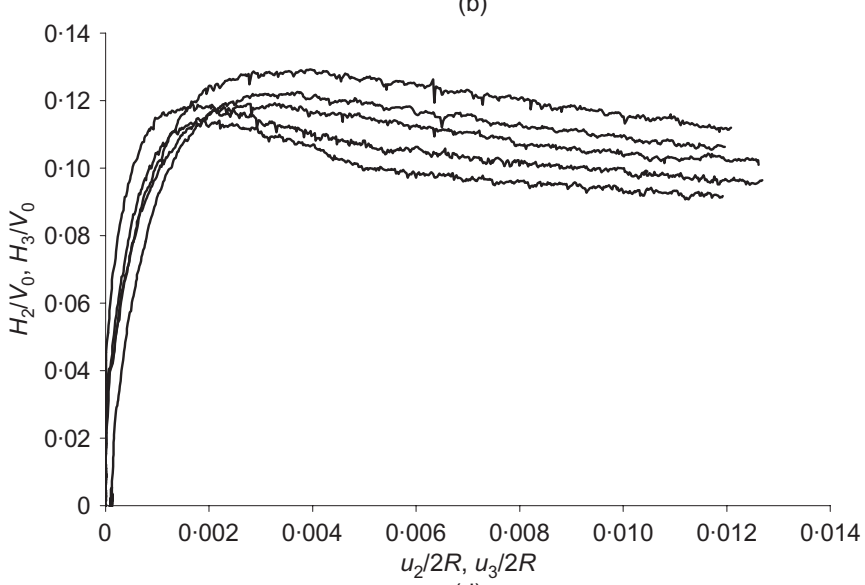

(d)

Fig. 4. Typical swipe experiment: (a) family of horizontal swipe curves (BB16); (b) family of horizontal swipes normalised by $V_{0}$; (c) family of horizontal load-displacement curves; (d) normalised family of horizontal load-displacement curves

Byrne (2000) for footings on clay and dense sand respectively. Fig. 4(a) shows the family of curves in load space, noting that although all loads are measured by the load cell only the relevant load paths are shown. This shows that the yield surface increases in size with an increase in the initial vertical load applied to the foundation, consistent with previous studies. Note that in this test the first, third and fifth swipes were along the direction of axis 2 (as defined in Fig. 2(b)) so that the relevant load path is $V: H_{2}$, whereas the second and fourth swipe are along the direction of axis 3 so that the relevant load path is $V: H_{3}$. There does not appear to be any difference due to the loading direction. This is confirmed by normalising the curves by the largest vertical load experienced prior to the swipe, $V_{0}$. The shape 
and size of the normalised curves given in Fig. 4(b) are similar. The load-displacement curves associated with this family of tests are plotted in Fig. 4(c). The peak horizontal load is mobilised fairly quickly after the translation commences. Fig. 4(d) shows that the normalised curves are also similar in load-displacement space.

Similar responses are evident for tests where rotations are applied to the foundation at constant vertical displacement. Fig. 5(a) compares the results from a horizontal swipe, a rotational swipe and a torsional swipe test. The plot shows that the yield surface size differs for each of the loading modes, and the shape varies slightly as well. The swipes in the horizontal plane show a larger yield surface than those in the rotational plane. The yield surface mapped out by torsional swipes is smaller still. Although the size of the yield surface in the respective planes differs, the three tests shown trace similar paths when normalised by the maximum pure load capacity in the respective direction. This is illustrated in Fig. 5(b), where the loads other than vertical are collapsed into a normalised deviator force

$$
x=\frac{X}{V_{0}}
$$

where the deviator force is given by

$$
X=\sqrt{\frac{\left(\frac{H_{2}}{h_{0}}\right)^{2}+\left(\frac{H_{3}}{h_{0}}\right)^{2}+\left(\frac{M_{2} / 2 R}{m_{0}}\right)^{2}+\left(\frac{M_{3} / 2 R}{m_{0}}\right)^{2}}{-2 a\left(\frac{H_{3} M_{2} / 2 R-H_{2} M_{3} / 2 R}{h_{0} m_{0}}\right)+\left(\frac{Q / 2 R}{q_{0}}\right)^{2}}}
$$

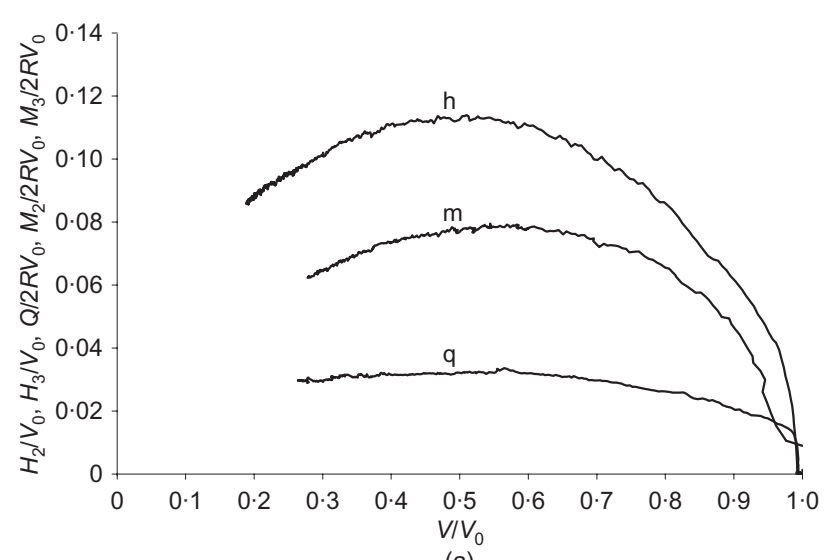

(a)

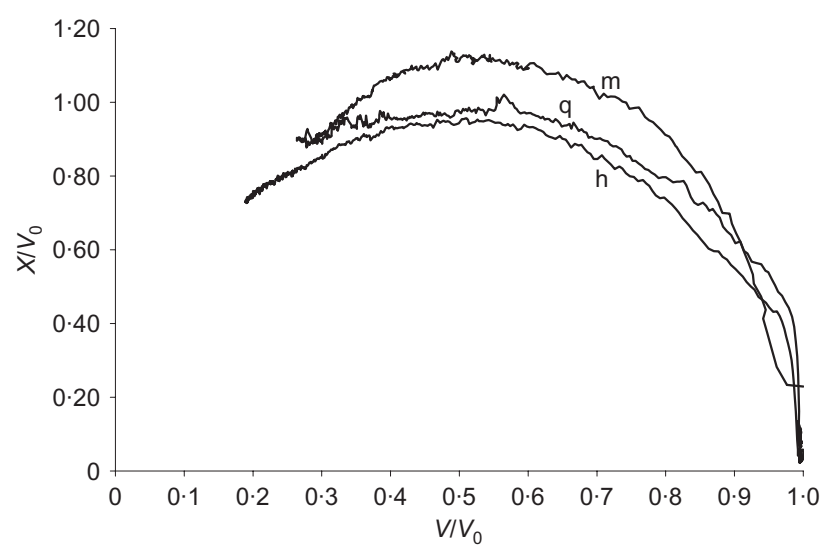

(b)

Fig. 5. Three different swipe tests: (a) normalised by $V_{0}$; (b) in the plane $X / V_{0}$
It is clear that the shapes for the different modes of loading are slightly different. We, however, assume that the shapes are the same, so as to simplify the fitting of equation (2) to the data. We also make the simplifying assumption that the values of the parameters $h_{0}, m_{0}$ and $q_{0}$ remain constant with footing penetration, although Byrne \& Houlsby (2001) suggest that $h_{0}$ is a function of footing embedment. Further swipes were carried out that use a combination of translation and rotation, either in-plane or out-of-plane. The results of all 46 pure swipe tests are collated in Fig. 6 using equation (4). This figure also shows the best-fit parabolic yield surface. The yield surface parameters, obtained by carrying out a least-squares regression of the data onto equation (2), are given by

$$
\begin{aligned}
& h_{0}=0.122, m_{0}=0.075, q_{0}=0.033 \\
& a=-0.112, \beta_{1}=0.76, \beta_{2}=0.76
\end{aligned}
$$

The yield surface parameters determined for the loose silica sand here agree well with previous studies on different densities and even different sands (Cassidy, 1999; Gottardi et al., 1999; Byrne \& Houlsby, 2001). Of course, these previous studies involved loading that is a subset of the loading patterns applied here.

A special set of swipe tests were carried out that involve changing the direction of the swipe during the test. For instance, Fig. 7 shows the load data from a test where initially the footing was horizontally translated $0.25 \mathrm{~mm}$ along axis 2 before being translated $1.75 \mathrm{~mm}$ along axis 3 .

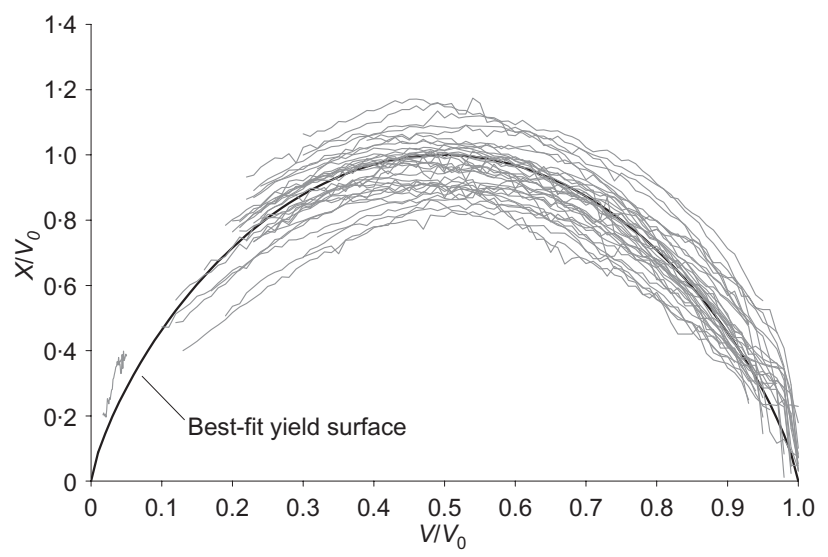

Fig. 6. All swipe tests in deviator plane with best-fit yield surface

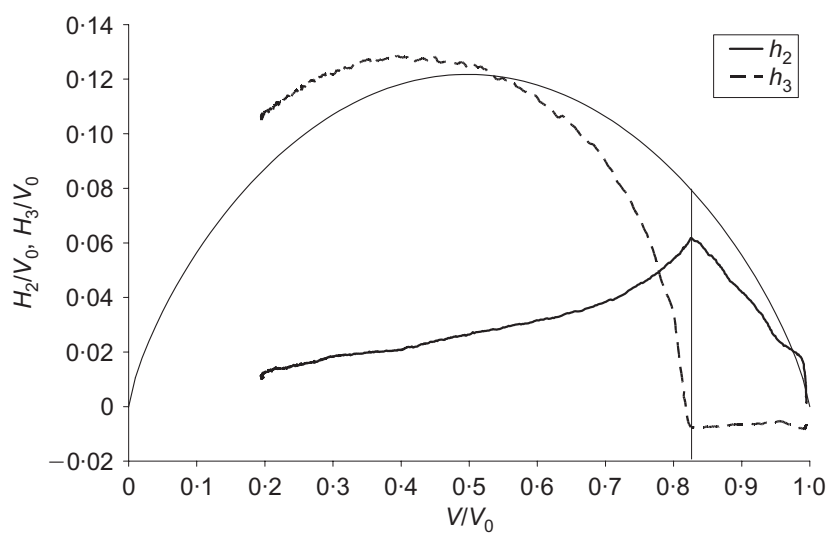

Fig. 7. Load paths traced by footing under combination of consecutive perpendicular horizontal translations 
Correspondingly, $\mathrm{H}_{2}$ increases and tracks around a yield surface. On changing the direction, $H_{2}$ drops while $H_{3}$ picks up and continues the track around the yield surface. For comparison the figure shows the yield surface for horizontal loads as defined by the parameter $h_{0}$ above. Also shown in the figure is a line that represents the point at which the direction changes. Note that in the experiment the loading rig is not infinitely stiff, and therefore after the change in direction there is still some movement along the axis 2 direction although the main translation is along axis 3 . This results in a slower reduction in $\mathrm{H}_{2}$ than would be predicted by the numerical model. Several different combinations of these tests (38 in total) are listed in Table 2 and include tests where a translation is followed by a rotation and vice versa.

\section{Hardening law}

Figure 8(a) shows the typical vertical load-displacement responses measured in the tests. Two tests were devoted solely to vertical loading, and the initial vertical loading curves from the swipe tests provided extra data. The small amount of scatter between the curves illustrates the repeatability of the tests and the uniformity in soil sample preparation. Also shown in Fig. 8(a) is the hardening law expression fitted to the vertical load-displacement curves. The expression has the form

$$
V_{0}=k_{1} w_{\mathrm{p}}\left[\frac{1+\left(w_{\mathrm{p}} / w_{1}\right)}{1+\left(w_{\mathrm{p}} / w_{2}\right)}\right]
$$

where $w_{\mathrm{p}}$ is the plastic component of the vertical displace-

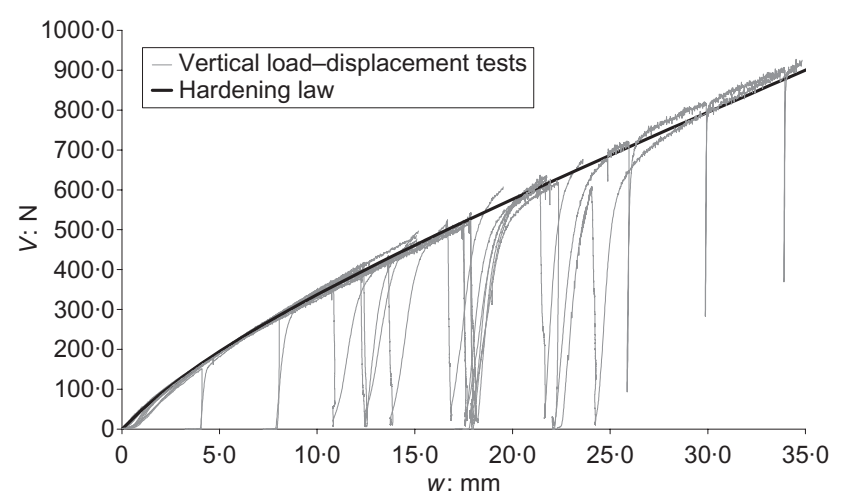

(a)

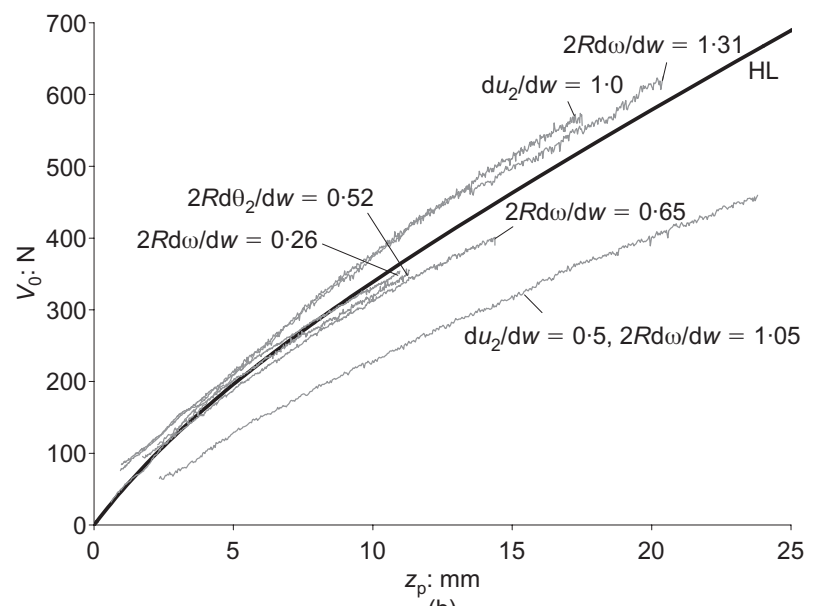

(b)

Fig. 8. Hardening relationship: (a) compared with vertical load-displacement results; (b) compared with radial displacement results ment (Cassidy et al., 2002). Note that Fig. 8(a) is presented in terms of the total vertical displacement, which consists of the plastic displacement (as described in equation (5)) and an elastic displacement (described in the next section). The parameters achieving the best fit for equation (5) are

$$
k_{1}=51.25 \mathrm{~N} / \mathrm{mm}, w_{1}=20.5 \mathrm{~mm}, w_{2}=8 \mathrm{~mm}
$$

However, in a similar way to the results reported by Byrne yrne \& Houlsby (2001), hardening as a function of the plastic vertical displacement did not capture the measured response completely. Analysis of the radial displacement experimental data showed that the pure vertical load capacity $V_{0}$ calculated by fitting the yield surface expression using the measured loads gives significantly higher values than predicted by the hardening law (that is, the yield surface is larger than predicted by the current vertical plastic penetration level). This implies that the hardening must be a function of the radial plastic movements (translations and rotations) as well as of the vertical movements. Equation (5) can be rewritten to incorporate radial hardening such that $V_{0}$ is a function of the total plastic displacement, as follows.

$$
V_{0}=k_{1} z_{\mathrm{p}}\left[\frac{1+\left(z_{\mathrm{p}} / w_{1}\right)}{1+\left(z_{\mathrm{p}} / w_{2}\right)}\right]
$$

The total plastic displacement can be obtained by summation of the incremental plastic displacement, given by

$$
\begin{aligned}
\dot{z}_{\mathrm{p}}= & \dot{w}_{\mathrm{p}}+c_{1} \sqrt{\dot{u}_{2 \mathrm{p}}^{2}+\dot{u}_{3 \mathrm{p}}^{2}}+c_{2} \sqrt{\left(2 R \dot{\theta}_{2 \mathrm{p}}\right)^{2}+\left(2 R \dot{\theta}_{3 \mathrm{p}}\right)^{2}} \\
& +c_{3}\left|2 R \dot{\omega}_{\mathrm{p}}\right|
\end{aligned}
$$

which now comprises all the plastic displacement components. The values for $k_{1}, w_{1}$ and $w_{2}$ remain as before, because they achieved the best fit for purely vertical displacement. In order to establish the new parameters for the model with radial hardening, both the hardening law and the yield surface parameters need to be adjusted until the results become consistent. The yield surface parameters presented previously represent the best-fit values for the model that includes radial hardening. The additional radial hardening parameters for equation (7) are

$$
c_{1}=1 \cdot 07, c_{2}=0.62, c_{3}=1.09
$$

Figure 8(b) shows that this hardening law matches the experimental data reasonably well. The best-fit values for the radial components of the hardening law are slightly larger than the values suggested by Byrne \& Houlsby (2001) for the horizontal and rotational components of hardening on a loose carbonate sand. Further work is required to understand the relationship between the nature and state of the soil and this component of the model.

\section{Elasticity}

To establish parameters to describe the elastic behaviour of the foundations several vertical unload-reload loops were performed during the vertical load displacement tests. This allows an assessment of the vertical elastic stiffness $K_{\mathrm{v}}$, and analysis of the data gives $K_{\mathrm{V}}=5.5 \mathrm{kN} / \mathrm{mm}$. The elastic stiffness for the other degrees of freedom can be derived from this vertical stiffness by considering the elastic stiffness matrix for circular footings, as follows. 


$$
\begin{aligned}
& \left\{\begin{array}{c}
\mathrm{d} V \\
\mathrm{~d} H_{2} \\
\mathrm{~d} H_{3} \\
\mathrm{~d} Q / 2 R \\
\mathrm{~d} M_{2} / 2 R \\
\mathrm{~d} M_{3} / 2 R
\end{array}\right\}=2 G R \\
& \times\left[\begin{array}{cccccc}
k_{\mathrm{v}} & 0 & 0 & 0 & 0 & 0 \\
0 & k_{\mathrm{h}} & 0 & 0 & 0 & -k_{\mathrm{c}} \\
0 & 0 & k_{\mathrm{h}} & 0 & k_{\mathrm{c}} & 0 \\
0 & 0 & 0 & k_{\mathrm{q}} & 0 & 0 \\
0 & 0 & k_{\mathrm{c}} & 0 & k_{\mathrm{m}} & 0 \\
0 & -k_{\mathrm{c}} & 0 & 0 & 0 & k_{\mathrm{m}}
\end{array}\right]\left\{\begin{array}{c}
\mathrm{d} w \\
\mathrm{~d} u_{2} \\
\mathrm{~d} u_{3} \\
2 R \mathrm{~d} \omega \\
2 R \mathrm{~d} \theta_{2} \\
2 R \mathrm{~d} \theta_{3}
\end{array}\right\}
\end{aligned}
$$

The stiffness coefficients can be established by finite element analysis, such as those derived by Doherty \& Deeks (2003) as $k_{\mathrm{v}}=2.904, k_{\mathrm{h}}=2.901, k_{\mathrm{m}}=0.548, k_{\mathrm{c}}=-0.208$ and $k_{\mathrm{q}}=0.918$. Knowing the vertical elastic stiffness, the shear modulus can be derived (in these tests $\mathrm{G} \approx 12.7 \mathrm{MN} /$ $\mathrm{m}^{2}$ ), and the entire elastic stiffness matrix can be established.

\section{Flow rule}

To assess the flow behaviour and therefore define the plastic potential requires tests that expand the yield surface in a predefined manner. In a radial displacement test the footing is moved into the soil at a fixed displacement ratio while the corresponding loads are measured. The footing is continually at yield. The combined load point must lie on the current yield surface, and the displacement ratio at that point enables the direction of plastic displacement at yield to be identified. Various radial displacement tests have been carried out to provide information about the flow rule, particularly in the torsional plane, where very limited experimental data are available.

The analysis of the data is carried out by considering the plastic deviatoric displacement direction evaluated from the measured displacement data. For the three-degree-of-freedom case Cassidy (1999) expressed the incremental plastic displacements at yield in the radial direction (that is, the displacement that is work conjugate to the load $X$ defined in equation (4)) as

$$
\mathrm{d} \xi_{\mathrm{p}, \text { experiment }}=\lambda \frac{\partial f}{\partial X}=\lambda \frac{2 X}{V_{0}^{2}}
$$

where $\lambda$ is a multiplier defining the magnitude of plastic displacement. This is derived from the continuity condition, which ensures that during yield the load point lies on the current yield surface and therefore holds for the true loading case. To allow comparisons of plastic displacements numerically predicted from measured loads and those actually followed in the experiments, equation (9) can be rewritten for the six-degree-of-freedom case as

$$
\begin{aligned}
& \mathrm{d} \xi_{\mathrm{p}, \text { experiment }}^{2}=\frac{1}{1-a^{2}}\left\{\left(h_{0} \mathrm{~d} u_{2 \mathrm{p}}\right)^{2}+\left(h_{0} \mathrm{~d} u_{3 \mathrm{p}}\right)^{2}\right. \\
& \left.\quad+\left[m_{0}\left(2 R \mathrm{~d} \theta_{2 \mathrm{p}}\right)\right]^{2}+\left[m_{0}\left(2 R \mathrm{~d} \theta_{3 \mathrm{p}}\right)\right]^{2}\right\} \\
& \quad+\frac{2 a h_{0} m_{0}}{1-a^{2}}\left[\mathrm{~d} u_{3 \mathrm{p}}\left(2 R \mathrm{~d} \theta_{2 \mathrm{p}}\right)-\mathrm{d} u_{2 \mathrm{p}}\left(2 R \mathrm{~d} \theta_{3 \mathrm{p}}\right)\right]+q_{0}^{2}\left(2 R \mathrm{~d} \omega_{\mathrm{p}}\right)^{2}
\end{aligned}
$$

If associated flow is assumed for the $X: V$ plane it is possible to obtain a theoretical prediction of displacements by differentiation of the yield surface function (equation (9)). The experimentally observed incremental plastic displacements $\left(\mathrm{d} \xi_{\mathrm{p}}: \mathrm{d} w_{\mathrm{p}}\right)$ were found, however, to require non- associated flow in this plane. The evidence for this is shown in Fig. 9, where the radial displacement test data have been plotted in terms of $\tan ^{-1}(X / V)$ against $\tan ^{-1}\left(\mathrm{~d} \xi_{\mathrm{p}} / \mathrm{d} w_{\mathrm{p}}\right)$. For comparison the figure shows predictions for associated flow and for various degrees of non-association using the flow rule given by

$$
\begin{aligned}
g(V, & \left.H_{2}, H_{3}, M_{3} / 2 R, M_{2} / 2 R, Q / 2 R\right) \\
= & \left(\frac{H_{2}}{\alpha_{\mathrm{h}} h_{0} V_{0}^{\prime}}\right)^{2}+\left(\frac{H_{3}}{\alpha_{\mathrm{h}} h_{0} V_{0}^{\prime}}\right)^{2}+\left(\frac{M_{2} / 2 R}{\alpha_{\mathrm{m}} m_{0} V_{0}^{\prime}}\right)^{2} \\
& +\left(\frac{M_{3} / 2 R}{\alpha_{\mathrm{m}} m_{0} V_{0}^{\prime}}\right)^{2}-2 a\left(\frac{H_{3} M_{2} / 2 R-H_{2} M_{3} / 2 R}{\alpha_{\mathrm{h}} \alpha_{\mathrm{m}} h_{0} m_{0} V_{0}^{\prime 2}}\right) \\
& +\left(\frac{Q / 2 R}{\alpha_{\mathrm{q}} q_{0} V_{0}^{\prime}}\right)^{2} \\
& -\left[\frac{\left(\beta_{3}+\beta_{4}\right)^{\left(\beta_{3}+\beta_{4}\right)}}{\beta_{3}^{\beta_{3}} \beta_{4}^{\beta_{4}}}\right]^{2}\left(\frac{V}{V_{0}^{\prime}}\right)^{2 \beta_{3}}\left(1-\frac{V}{V_{0}^{\prime}}\right)^{2 \beta_{4}}=0
\end{aligned}
$$

where the parameter $V_{0}^{\prime}$ represents the maximum pure vertical load for the plastic potential such that it intersects the yield surface at the point of the current load state. $\beta_{3}$ and $\beta_{4}$ represent shaping parameters, and $\alpha_{\mathrm{h}}, \alpha_{\mathrm{m}}$ and $\alpha_{\mathrm{q}}$ are association factors as described by Cassidy (1999), Cassidy et al. (2002), Houlsby \& Cassidy (2002) and Cassidy \& Cheong (2005). In order to simplify the analysis of the data the curvature parameters $\beta_{3}$ and $\beta_{4}$ are assumed to be equal. The association parameters $\alpha_{\mathrm{h}}$ and $\alpha_{\mathrm{m}}$ are taken to be equal, because the number of tests carried out does not allow any distinction to be deduced with confidence. However, it is necessary to use a higher value for $\alpha_{\mathrm{q}}$ because the degree of non-association is much higher for this direction. The summary best-fit parameters are

$$
\beta_{3}=\beta_{4}=0.52, \alpha_{\mathrm{h}}=\alpha_{\mathrm{m}}=3 \cdot 3, \alpha_{\mathrm{q}}=5 \cdot 0
$$

Curves representing this combination of parameters are shown in Fig. 9; note that these parameters are used in the numerical predictions shown in the sections that follow. If, however, it is necessary to make all the association parameters equal, the best-fit parameters are

$$
\beta_{3}=\beta_{4}=0.52, \alpha_{\mathrm{h}}=\alpha_{\mathrm{m}}=\alpha_{\mathrm{q}}=3 \cdot 7
$$

In the radial displacement tests the ratio of the applied displacements is held constant. Therefore a large number of experiments are required to collect a range of information on the degree of non-association in a plane. An alternative approach to obtain information about the flow behaviour is

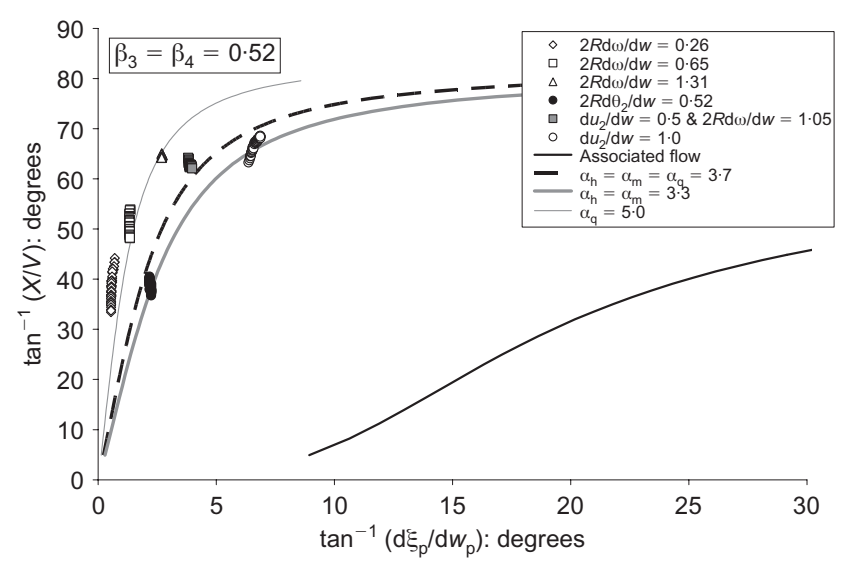

Fig. 9. Radial displacement tests and predictions for various degrees of non-association 
to carry out constant vertical load tests. These are similar to swipe tests, but the vertical load is held constant rather than the vertical displacement. It is not yet possible to carry out this type of test with the equipment described here.

The study of flow has concentrated on planes that include vertical load and displacement. For plastic displacements in the rotational-horizontal $(M, H)$ planes, associated flow has been assumed. This is based on the experimental evidence from three-degree-of-freedom investigations such as reported by Gottardi et al. (1999), Martin \& Houlsby (2000, 2001), Byrne \& Houlsby (2001), Cassidy et al. (2002) and Houlsby \& Cassidy (2002). The series of tests reported in this paper has not focused on investigating this aspect of behaviour.

\section{NUMERICAL PREDICTIONS}

The experimental work above forms the basis for developing numerical models, such as that reported by Houlsby \& Cassidy (2002), and in particular extending them from three to six degrees of freedom. Based on the work of Martin \& Houlsby (2000) and Houlsby \& Cassidy (2002), a numerical footing plasticity model has been developed called ISIS. The remainder of this paper will outline the development of this model to account for six degrees of freedom and the resulting numerical predictions of the experimental work. A summary of the parameters determined from the analysis of the experimental work is shown in Table 3. One of the developments derived from the experimental work was to incorporate, into ISIS, hardening as a function of radial displacements rather than solely as a function of the vertical plastic penetration.

\section{Radial displacement tests}

The numerical simulation of the radial displacement tests represents challenging analyses because the yield surface expands at every increment of the test. Fig. 10 shows the measured and numerically predicted responses for the radial test involving vertical and torsional displacements at a ratio of $2 R \mathrm{~d} \omega / \mathrm{d} w=1 \cdot 31$. Note that in the experiment the imposed displacement path relates to the total displacements, and the imposed plastic displacement ratios may vary slightly during the test (depending on the loads and the elastic response of the footing). The prediction includes both the radial-hardening model and the vertical-only hardening law. It is clear that by using a radial-hardening rule a much

Table 3. ISIS best-fit parameters

\begin{tabular}{l|c|c}
\hline Parameter & Value & Model feature \\
\hline$h_{0}$ & $0 \cdot 122$ & Yield surface \\
$m_{0}$ & $0 \cdot 075$ & \\
$q_{0}$ & $0 \cdot 033$ & \\
$a$ & $-0 \cdot 112$ & \\
$\beta_{1}$ & $0 \cdot 76$ & \\
$\beta_{2}$ & $0 \cdot 76$ & \\
$k_{1}$ & $51 \cdot 25$ & \\
$w_{1}$ & $20 \cdot 5$ & \\
$w_{2}$ & 8 & \\
$c_{1}$ & 1.07 & Flow rule \\
$c_{2}$ & $0 \cdot 62$ & \\
$c_{3}$ & $1 \cdot 09$ & \\
$\alpha_{\mathrm{h}}$ & $3 \cdot 3$ & \\
$\alpha_{\mathrm{m}}$ & $3 \cdot 3$ & \\
$\alpha_{\mathrm{q}}$ & $5 \cdot 0$ & \\
$\beta_{3}$ & 0.52 & \\
$\beta_{4}$ & 0.52 & \\
\hline
\end{tabular}

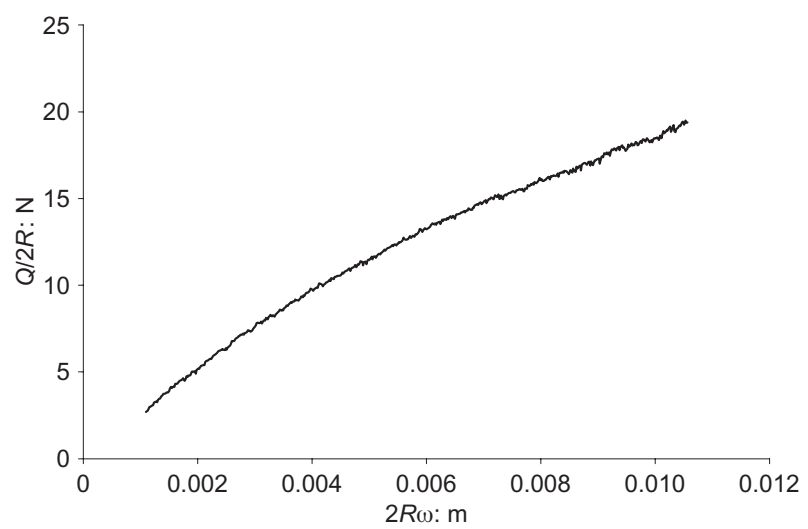

(a)

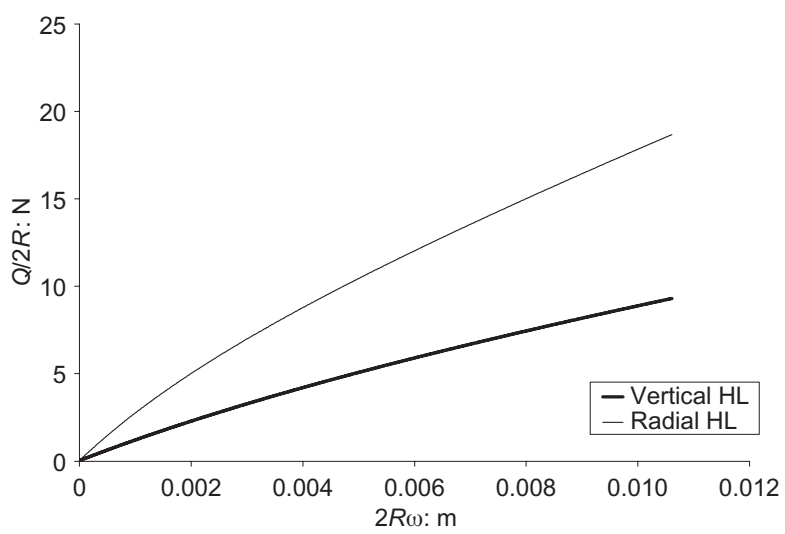

(b)

Fig. 10. Radial displacement test BB34 $(2 R \mathrm{~d} \omega / \mathrm{d} w=1 \cdot 31)$ : (a) load-displacement experimental results (b) load-displacement numerical prediction

better agreement in load magnitude with the experimental data is predicted.

In the radial displacement test shown in Fig. 11 a combination of three different motions was applied to the footing. The footing was twisted and displaced horizontally while at the same time penetrated into the soil. The prescribed displacement ratios were $\mathrm{d} u_{2} / \mathrm{d} w=0.5$ and $2 R \mathrm{~d} \omega / \mathrm{d} w$ $=1 \cdot 31$. In this case the prediction using the radial-hardening model slightly overpredicts the results in the torsional plane, whereas the vertical hardening law underestimates the loads.

Swipe tests

Following the experimental procedure, a numerical swipe test proceeds by penetrating the footing vertically into the ground and thereby establishing the load state to be at the apex of the yield surface, with a size $V_{0}$ determined by the hardening law. After reaching the required vertical displacement, the increment of total vertical displacement is kept constant while displacement paths in the other degrees of freedom are input, and the corresponding six loads are calculated.

The displacements applied during the swipe phase, and the corresponding plastic components, are relatively small. This is why additional hardening due to radial plasticity in these tests is not significant. Therefore uncertainty in the hardening law parameters $c_{1}, c_{2}$ and $c_{3}$ visible in the differences between experimental data and the best-fit radial hardening law predictions shown in Fig. 8(b) are not expected to influence the quality of swipe test predictions to a significant extent.

The swipe test data where a single movement (translation, 

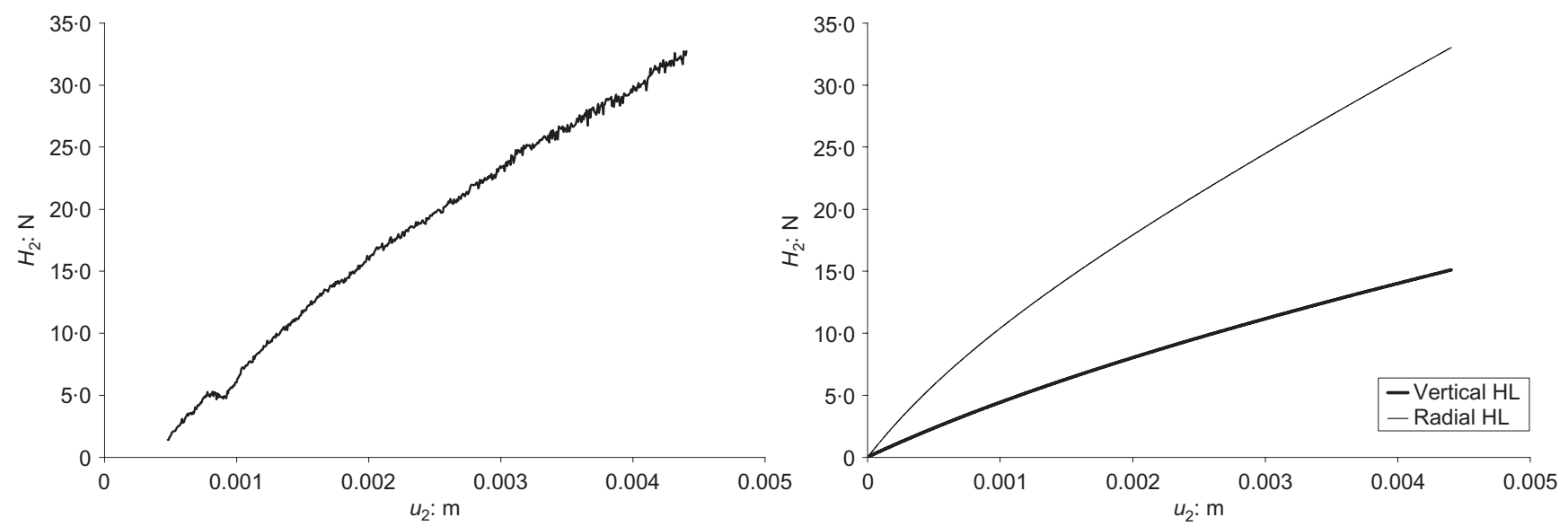

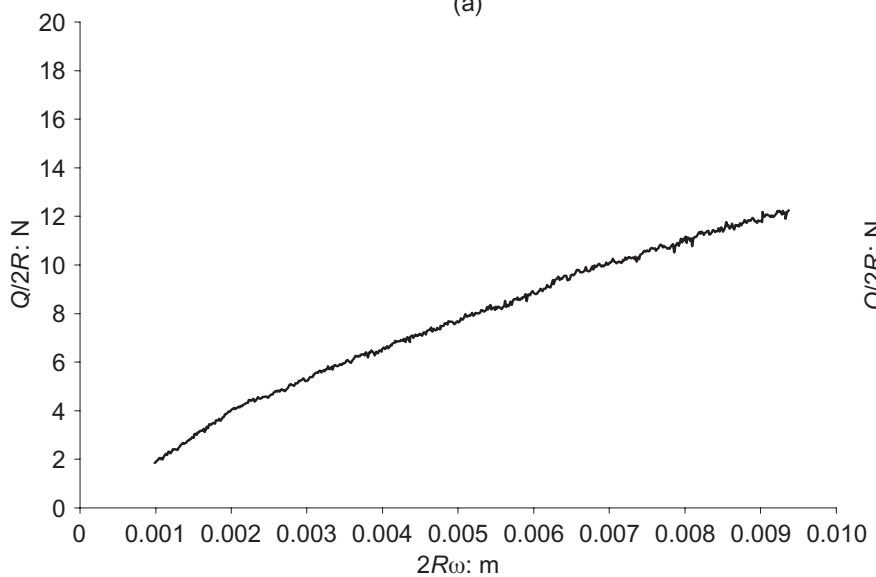

(c)

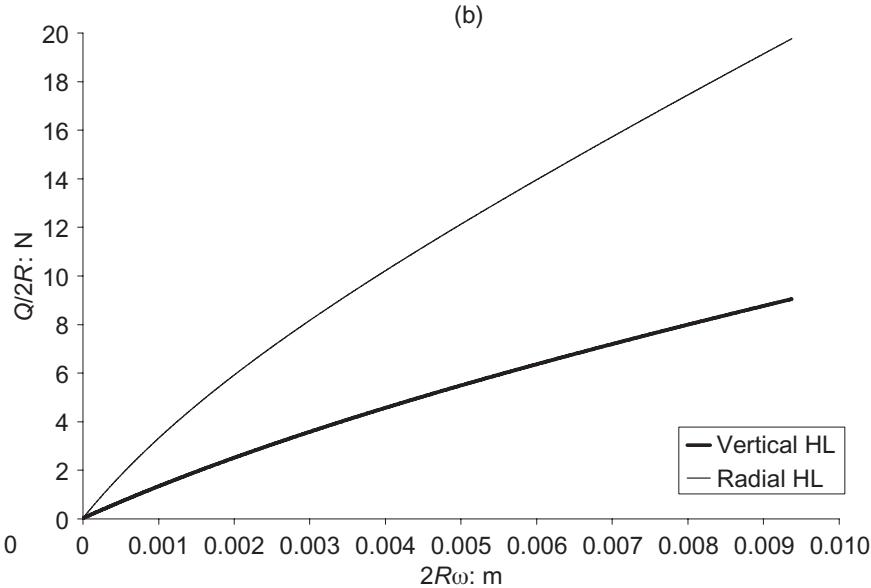

(d)

Fig. 11. Radial displacement test $\mathrm{BB} 39\left(\mathrm{~d} u_{2} / \mathrm{d} w=0 \cdot 5\right.$ and $\left.2 R \mathrm{~d} \omega / \mathrm{d} w=1 \cdot 05\right)$ in: (a) horizontal load-displacement experimental results; (b) horizontal load-displacement numerical prediction; (c) torsion load-displacement experimental results; (d) torsion loaddisplacement numerical prediction

rotation or combinations) was applied to the footing were used to define the yield surface parameters. Some of the single-movement swipe tests were predicted numerically to show accuracy of these parameters. However, Houlsby \& Cassidy (2002) and Cassidy et al. (2002) provide several retrospective simulations of horizontal and moment swipe data, and so therefore they are not repeated here. This previous work did not examine the torsional swipe tests, and so we present a numerical prediction here.

Figure 12 shows the measured and predicted responses in a torsional swipe test. With the plastic potential parameters as derived from the experimental work (shown in Fig. 9), the predicted load-displacement response exhibits a pronounced peak, strain-softening and a low residual torsional capacity. This has not been observed in the experimental data, where there is virtually no softening after the peak load has been reached. The underprediction of torsion is reflected in the load plane (compare Figs 12(a) and 12(b)). The remarkable softening in the prediction is due principally to an extreme sensitivity to the way flow is modelled, and this aspect of the modelling requires further refinement. For comparison, if the flow parameters are derived so that a best fit of the torsional swipe (from Fig. 12) is obtained as shown in Fig. 13(a), then it is not possible, using the current formulation, to match the radial displacement test data such as that from Fig. 10 accurately (shown in Fig. 13(b)).

\section{Swipe testing with changing displacement path}

An important aspect of moving from a three- to a sixdegree-of-freedom model is the ability to predict the response of the footing to a change in loading direction. As described previously, several swipe tests incorporated a change in displacement direction during the swipe, and an example response was shown in Fig. 7. A numerical prediction of this result is shown in Fig. 14. The numerical test involved preloading the footing to the target vertical displacement, followed by horizontal translation, while keeping the vertical displacement constant. After a short translation the footing was translated perpendicular to the original direction.

The prediction matches the experimental data well for the combined horizontal swipe shown in Fig. 14. The slight difference in the prediction of the change in direction in load space (that is, smaller vertical load) is likely to be due to an overestimation of the shear modulus. It is also important to be aware that the input data for the numerical simulations were idealised from the experimental data. In the experiment $u_{2}$ increased slightly after the application of $u_{3}$. There were also some minor movements of the other degrees of freedom. If the actual experimental displacement paths are used for input into the numerical model a slightly closer fit to the experiment is obtained.

The results from a numerical simulation of a second complex swipe test are shown in Fig. 15, where reasonably good agreement is evident. The overprediction of horizontal load by the numerical model is attributed largely to this curve falling slightly below the average curve that $h_{0}$ is based on. The result in the torsional direction is less good, as with the prediction of the single torsion swipe. While in load space the prediction is reasonable, the numerical loaddisplacement curve does not provide a good match to the experimental data, again showing much stronger softening. 

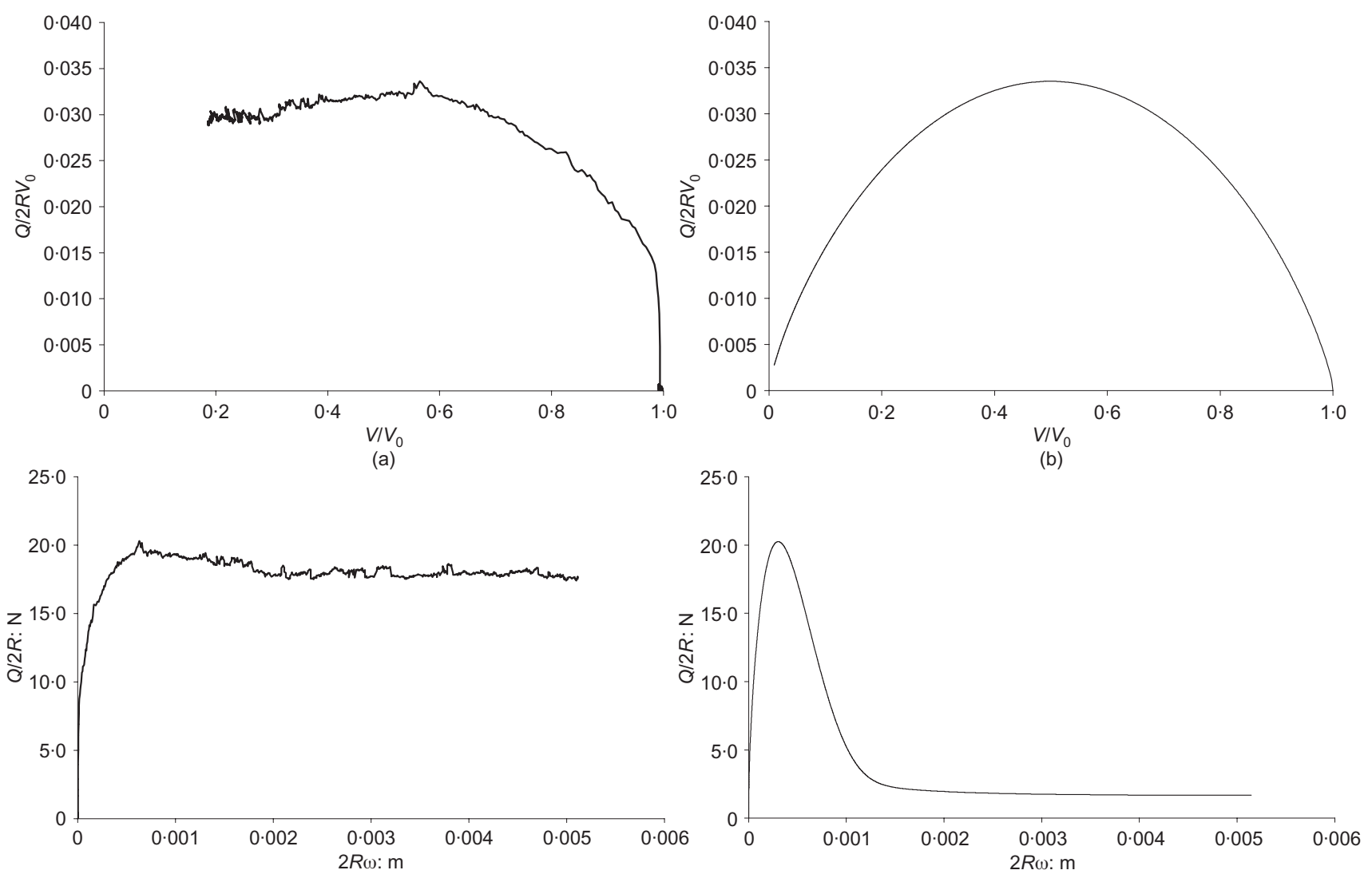

(c)

(d)

Fig. 12. Torsional swipe BB32: (a) load space experimental results; (b) load space numerical prediction; (c) load-displacement experimental results; (d) load-displacement numerical prediction

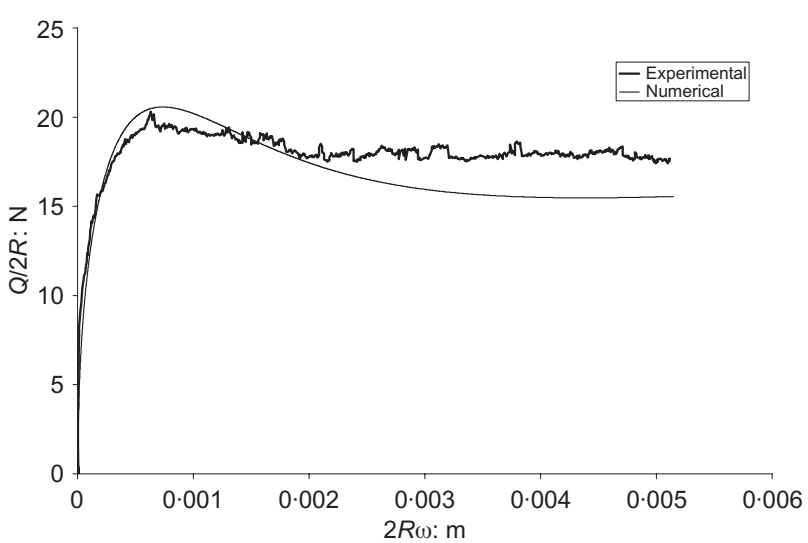

(a)

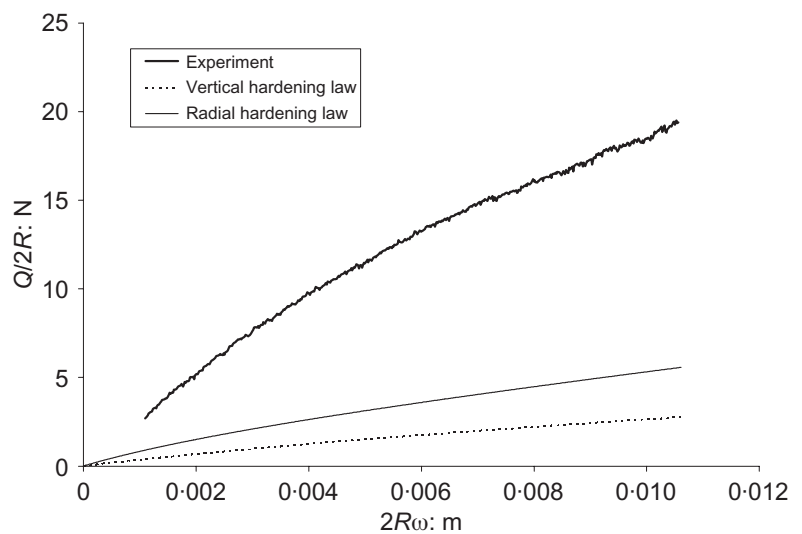

(b)

Fig. 13. Comparison of results using flow parameters derived to match torsional swipe test: (a) torsional swipe results (BB32; Fig. 12); (b) radial displacement results (BB34; Fig. 10)
As highlighted in the previous section further work is required to address this shortcoming in the model.

In carrying out the retrospective analyses of the swipe tests and radial displacement tests it was evident that an accurate determination of the shear modulus $G$ is important. Unload-reload loops in the vertical load-displacement tests allow the shear modulus to be estimated; however, typically these loops are hysteretic in character, and so assessing the modulus requires some judgement.

\section{CONCLUSION}

The development of hardening plasticity models for representing foundation response has been dependent on both experimental and theoretical development. Initially, experimental research on three-degree-of-freedom loading allowed the development of models applicable for planar loading (and structures). Though the theoretical framework describing the extension to a six-degree-of-freedom model had been suggested, this paper describes the results of an experimental programme required to verify those extensions and to derive numerous model parameters.

Specifically, a series of vertical load-displacement tests, swipe tests and radial displacement tests were carried out using a loading device capable of applying general loading to model foundations. This represents the first comprehensive set of experimental evidence of the load-displacement behaviour of a shallow foundation under true six-degree-of-freedom loading. The footing used in the experimental work was a rough circular flat foundation, and it was tested on loose silica sand.

The results have allowed the yield surface and plastic potential expressions for a six-degree-of-freedom plasticity model formulation to be assessed. A hardening law was suggested that included radial hardening components similar to work reported by Byrne \& Houlsby (2001). The elastic 


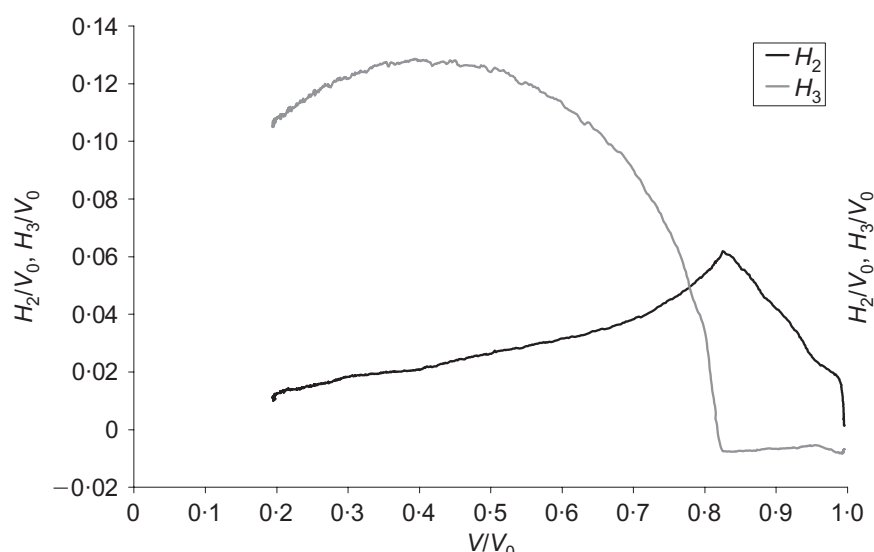

(a)

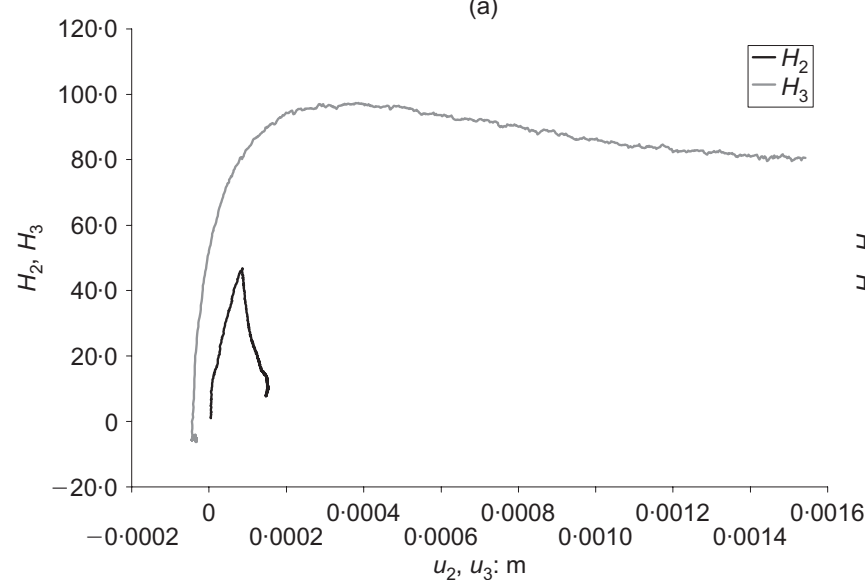

(c)

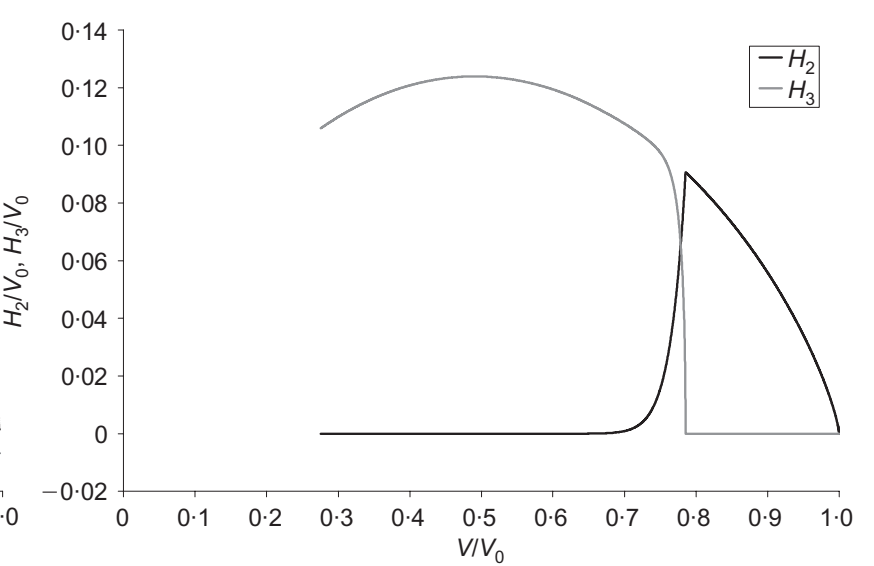

(b)

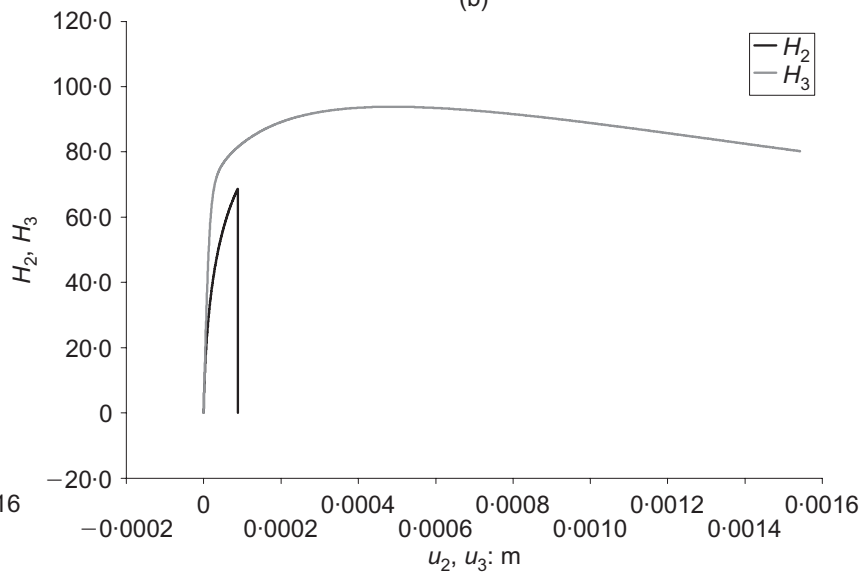

(d)

Fig. 14. Consecutive swipe BB19: (a) load space experimental results; (b) load space numerical prediction; (c) load-displacement experimental results; (d) load-displacement numerical prediction
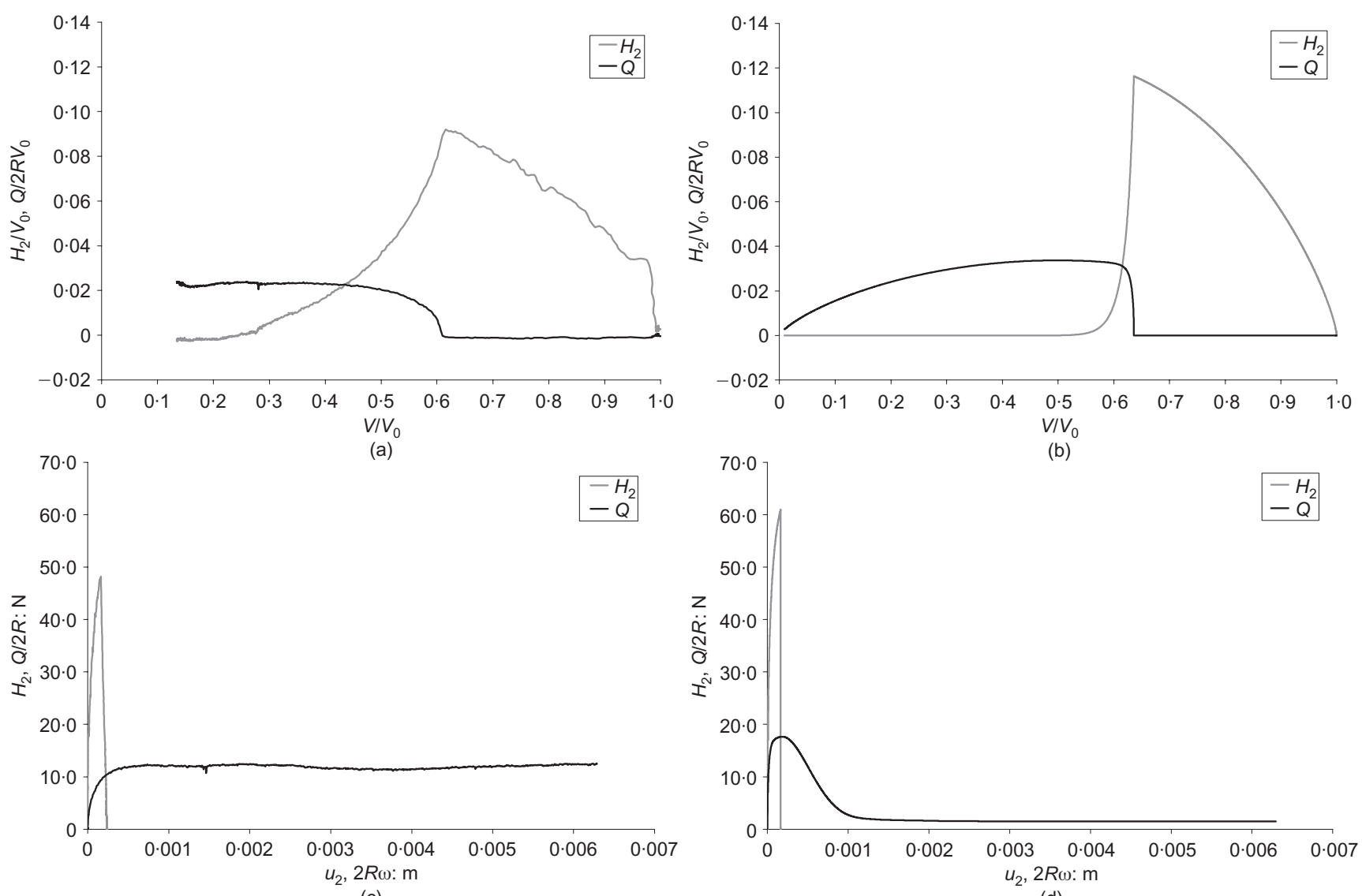

(c)

(d)

Fig. 15. Consecutive swipe BB27: (a) load space experimental results; (b) load space numerical prediction; (c) load-displacement experimental results; (d) load-displacement numerical prediction 
stiffness was derived from unload-reload loops of vertical load-displacement tests. Finally, best-fit values for the plasticity model parameters in six degrees of freedom were evaluated and presented.

Retrospective analyses of the experiments using a numerical formulation of the plasticity model, named ISIS, showed a good agreement with the experimental data. However, further research is required to increase the confidence in the radial hardening law parameters as well as the flow rule parameters, especially in the torsional direction.

\section{ACKNOWLEDGEMENTS}

The first author gratefully acknowledges the support of an International Postgraduate Research Scholarship of Australia and the University of Western Australia Postgraduate Students Association Research Travel Award. The work described in this paper forms part of a programme of collaboration between the University of Oxford and the University of Western Australia funded under ARC International Linkage Award LX0560459.

The experimental equipment described in this paper was developed in Oxford and funded by the Lubbock Trustees, the Royal Society, EPSRC and the Department of Engineering Science at Oxford. The authors are grateful for the work of Clive Baker and Chris Waddup, who constructed the loading device, and to Llywellyn ap Gwillym, Ed Stiles and Rachel Williams, who have contributed to the development of the equipment.

\section{NOTATION}

$$
\begin{aligned}
& a \text { eccentricity of the yield surface } \\
& c_{1}, c_{2}, c_{3} \text { radial hardening parameters } \\
& f \text { yield surface expression } \\
& G \text { shear modulus } \\
& g \text { plastic potential expression } \\
& \mathrm{H}, \mathrm{H}_{2}, \mathrm{H}_{3} \text { horizontal force } \\
& h, h_{2}, h_{3} \text { normalised horizontal force } \\
& h_{0}, m_{0}, q_{0} \text { maximum normalised force } \\
& K_{v} \quad \text { vertical elastic stiffness } \\
& k_{v}, k_{h}, k_{m}, k_{c}, k_{q} \text { elastic stiffness coefficients } \\
& k_{1}, w_{1}, w_{2} \text { hardening expression parameters } \\
& M, M_{2}, M_{3} \text { moment } \\
& m, m_{2}, m_{3} \text { normalised moment } \\
& Q \text { torsion } \\
& q \text { normalised torsion } \\
& R \text { footing radius } \\
& u, u_{2}, u_{3} \text { horizontal displacement } \\
& V \text { vertical force } \\
& V_{0} \text { maximum vertical force applied to foundation } \\
& V_{0}^{\prime} \quad \text { vertical load associated with plastic potential } \\
& v \text { normalised vertical force } \\
& w \text { vertical displacement } \\
& X \text { deviator force } \\
& x \text { normalised deviator force } \\
& z \text { total displacement } \\
& \alpha_{h}, \alpha_{m}, \alpha_{q} \text { association factors for plastic potential } \\
& \beta_{1}, \beta_{2}, \beta_{12} \text { shaping parameters for the yield surface } \\
& \beta_{3}, \beta_{4}, \beta_{34} \text { shaping parameters for the plastic potential } \\
& \theta, \theta_{2}, \theta_{3} \text { rotation } \\
& \lambda \text { plastic multiplier } \\
& \xi \text { displacement conjugate to deviator force } \\
& \omega \text { twist }
\end{aligned}
$$

Subscript

p plastic displacement

\section{REFERENCES}

Bienen, B., Byrne, B. W. \& Houlsby, G. T. (2005). Six degree-offreedom loading of a circular flat footing on loose sand: Experimental data, Report No OUEL 2289/05. Oxford: Department of Engineering Science, University of Oxford.

Butterfield, R., Houlsby, G. T. \& Gottardi, G. (1997). Standardised sign conventions and notation for generally loaded foundations. Géotechnique 47, No. 4, 1051-1054; corrigendum 48, No. 1, 157.

Byrne, B. W. (2000). Investigations of suction caissons in dense sand. DPhil. thesis, University of Oxford.

Byrne, B. W. \& Houlsby, G. T. (2001). Observations of footing behaviour on loose carbonate sands. Géotechnique 51, No. 5, $463-466$.

Byrne, B. W. \& Houlsby, G. T. (2005). Investigating 6 degree-offreedom loading on shallow foundations. Proceedings of the international symposium on frontiers in offshore geotechnics (ISFOG), Perth, 477-482.

Cassidy, M. J. (1999). Non-linear analysis of jack-up structures subjected to random waves. DPhil. thesis, University of Oxford.

Cassidy, M. J. and Bienen, B. (2002). Three-dimensional numerical analysis of jack-up structures on sand. Proc. 12th Int. Offshore and Polar Engineering Conf., Kitakyushu, 807-814.

Cassidy, M. J. \& Cheong, J. (2005). The behaviour of circular footings on sand subjected to combined vertical-torsion loading. Int. J. Phys. Model. Geotech. 5, No. 4, 1-14.

Cassidy, M. J., Byrne, B. W. and Houlsby, G. T. (2002). Modelling the behaviour of circular footings under combined loading on loose carbonate sand. Géotechnique 52, No. 10, 705-712.

Doherty, J. P. \& Deeks, A. J. (2003). Elastic response of circular footings embedded in a non-homogeneous half-space. Géotechnique 53, No. 8, 703-714.

Gottardi, G. \& Butterfield, R. (1993). On the bearing capacity of surface footings on sand under general planar loads. Soils Found. 33, No. 3, 68-79.

Gottardi, G., Houlsby, G. T. and Butterfield, R. (1999). Plastic response of circular footings on sand under general planar loading. Géotechnique 49, No. 4, 453-469.

Hansen, J. B. (1961). A general formula for bearing capacity, Bulletin No 11. Copenhagen: Danish Geotechnical Institute.

Hansen, J. B. (1970). A revised and extended formula for bearing capacity, Bulletin No 28, pp. 5-11. Copenhagen, Danish Geotechnical Institute.

Houlsby, G. T. \& Cassidy, M. J. (2002). A plasticity model for the behaviour of footings on sand under combined loading. Géotechnique 52, No. 2, 117-129.

Martin, C. M. (1994). Physical and numerical modelling of offshore foundations under combined loads. DPhil thesis, University of Oxford.

Martin, C. M. \& Houlsby, G. T. (2000). Combined loading of spudcan foundations on clay: laboratory tests. Géotechnique $\mathbf{5 0}$, No. 4, 325-338.

Martin, C. M. \& Houlsby, G. T. (2001). Combined loading of spudcan foundations on clay: numerical modelling. Géotechnique 51, No. 8, 687-700.

Meyerhof, G. G. (1953). The bearing capacity of foundations under eccentric and inclined loads. Proc. 3rd Int. Conf. Soil Mech. Found. Engng, Zurich, 1, 440-445.

Nova, R. \& Montrasio, L. (1991). Settlement of shallow foundations on sand. Géotechnique 41, No. 2, 243-256.

Schnaid, F. (1990). A study of the cone-pressuremeter test in sand. DPhil thesis, University of Oxford.

Stewart, D. (1965). A platform with six degrees of freedom. Proc. Instn Mech. Engrs 180, No. 15, 371-384.

Tan, F. S. C. (1990). Centrifuge and numerical modelling of conical footings on sand. $\mathrm{PhD}$ thesis, University of Cambridge.

Vesic, A. S. (1973). Analysis of ultimate loads of shallow foundations. J. Soil Mech. Found. Div. ASCE 99, No. 1, 45-73.

Vesic, A. S. (1975). Bearing capacity of shallow foundations. In Foundation engineering handbook (eds H. F. Winterkorn and H. Y. Fang), pp. 121-147. New York: Van Nostrand. 


\title{
DISCUSSION
}

\section{Investigating six-degree-of-freedom loading of shallow foundations on sand}

\author{
B. BIENEN, B. W. BYRNE, G. T. HOUlSBY and M. J. CASSIDY (2005). Géotechnique 56, No. 6, \\ $367-379$
}

\section{V. Morris, Geoneering/Bryant Consultants, Dallas}

The authors have presented an impressive set of laboratory experiments investigating the elasto-plastic behaviour of circular shallow foundations. This is particularly valuable as load conditions start to approach failure. However, most such foundations will (hopefully) spend most of their operating lives at lower stress levels, in which region elasticity would normally be assumed to be the dominating consideration in evaluating response- - even though it is possibly the shortest section in the paper.

In the elastic stiffness matrix for circular footings, though, I would query the need to use stiffness coefficients from finite element analysis, when most engineers are unlikely to do this as a matter of course, particularly when perfectly good analytic results are available, which will generally speaking be a designer's first reference point. If, in the vertical direction, for instance, the conventional equation $\mathrm{d} V=4 G R \mathrm{~d} w /(1-v)$ is used, then an identical result to Doherty \& Deeks (2003) is produced, if a Poisson's ratio $v$ $=0.311$ is assumed. Clearly, in real life, there would be some latitude in the value of Poisson's ratio that might be assumed, but in reality the likely range is very small and in most dry sands would be assumed to be between 0.3 and $0 \cdot 35$ (the controlling factor in real life being the degree of saturation of any sand). Ideally this should be measured independently in some way (as indeed should $G$, although one then has the problem of deciding where this should be, and what the appropriate stress level might be). The paper doesn't give any guidance on this important matter, the authors having been satisfied on this occasion with backcalculating an equivalent value of $G$ from Doherty \& Deeks' vertical stiffness coefficient after the load test. However, this is not usually a luxury available to a practising designer, and still basically produces a single value of modulus, without any differentiation as to stress level or position under the foundation. Some independent prior determination of the soil modulus would be desirable, so that a comparison could be made with the results of a prior reasonable prediction. The Leighton Buzzard sand used was indeed a fairly well-established soil, although the soil characteristics listed in Table 1 do not extend to any independent value of modulus.

It is not intended to trivialise the determination of modulus (which might have been done perhaps in situ with a bender element, although in real life laboratory tests might also be conducted). However, in the absence of any independent experimental data, and if one is simply going to assign a single value of modulus to an assumed homogeneous subsoil, then use of the equivalent elastic stiffness coefficients would seem to be about as good an assumption as any other, and has the advantage of being well defined. (The great advantage of using numerical solutions like Doherty \& Deeks is in cases of significant embedment, or when the soil stiffness is known to vary with depth in a well-defined power law.)

The discusser would suggest that in general design there is not yet the need to deviate from using established analytic results, most easily by writing $k_{\mathrm{v}}=2 /(1-v), \quad k_{\mathrm{h}}=$ $4 /(3(1-v)), k_{\mathrm{q}}=\frac{2}{3}, k_{\mathrm{m}}=1 /(3-3 v)$ and $k_{\mathrm{c}}=4 \pi /(3-3 v)$, although discussion on the details is welcomed. While there may still be some debate about the optimum nature of the latter of these terms, since in reality the limiting factor on the accuracy of any calculation will be the determination of $G$, other considerations are likely to be secondary in comparison. If a significantly more complicated problem is encountered, then it is probably easiest to perform a numerical computation directly. For reasonably uniform soil, the elastic solutions are in fact quite good-the major exception being in the nature of the off-diagonal term $k_{\mathrm{c}}$ in the stiffness matrix, which (if results like Doherty \& Deeks are anything to go by) is substantially overestimated by elastic theory. This discrepancy is probably due to the fact that the relevant deflections are very sensitive to assumed behaviour at the edge of the foundation, where non-linear effects will be most prominent, and where in practice localised yielding will occur even at low stress levels. If the authors are aware of a good study of this problem, the discusser would be interested to hear about it.

Incidentally, the relative density of the soil tested in this study was unusually loose, at only $5 \%$, with no other inplace density tested. Without wishing to trivialise the difficulties of conducting such an impressive experimental programme, readers would no doubt be curious to know whether there was a particular explanation of this, as it would presumably have been easier to test the sand in a somewhat denser state, which would also correspond more closely to normal field conditions.

\section{Authors' reply}

The authors thank Dr Morris for his interest in their paper.

Dr Morris states that, as most foundations would be designed not to be near failure, then their response would be dominated by elasticity, while the paper concentrated on foundations undergoing larger plastic deformations. This viewpoint is perhaps conditioned from onshore practice. In offshore foundation design, which provided much of the motivation for the research, there are a number of foundation types (notably the spudcans of jack-up units) where the foundation inevitably undergoes large plastic deformation during installation and possibly even during service. Furthermore, we consider the elasticity problem (even for the full six-degree-of-freedom case) to be relatively well understood, and so have concentrated our research efforts on inelastic behaviour.

Dr Morris queries our use of the Doherty \& Deeks (2003) solutions for elastic response, implying that practising engineers would not have access to such techniques, and that a similar result could have been achieved by adopting a conventional solution and a Poisson's ratio $v=0 \cdot 311$. However, no dry sand (as was tested) has a Poisson's ratio this high, with measured values being typically in the range 0.15 to 
$0 \cdot 2$. The common practice of adopting a Poisson's ratio in the region of $0 \cdot 3$ appears to be borrowed from experience of metal elasticity, and is inappropriate in geotechnical applications. While not suggesting that finite element methods need to be used to determine elasticity response routinely, in our view published solutions such as those of Doherty \& Deeks (2003) are the best available means for modelling elastic behaviour (given of course the restrictions this implies), and practising engineers should be encouraged to use these best available methods. If they do not, then what purpose does a journal such as Géotechnique serve?

We agree that it would have been desirable to have had an independent measurement of shear modulus, and its variation with depth, by using bender elements, but such measurements were not part of our experimental programme, which was focusing on inelastic response.

Dr Morris quotes a series of 'established' analytical results, but does not quote their source. We have the following comments on the values he uses.

(a) We have not previously seen the expression he gives for $k_{\mathrm{h}}$. The usual expressions, both of which involve approximations, are $k_{\mathrm{h}}=4 /(2-v)$ or $k_{\mathrm{h}}=16(1-v) /$ $(7-8 v)$. We note, however, that these reduce to the same value as Morris's at $v=0 \cdot 5$.

(b) We are not familiar with his expression for $k_{\mathrm{c}}$. This expression is, however, inconsistent with the known solution at $v=0 \cdot 5$, which is $k_{\mathrm{c}}=0$.
Useful discussions of the above issues can be found in Bell (1991) and Ngo Tran (1996).

The final point that Dr Morris raises is in relation to the choice of a very low relative density for the testing programme. As is well known, one problem with laboratoryfloor model testing in sand is that, if medium to high relative densities are used, then the dilation of the sand can be excessive, and the angle of friction correspondingly too high. One solution is to test at a lower relative density in the laboratory, so that dilation rates in laboratory and field are comparable. For this reason we believe that our data are relevant to significantly higher relative densities in the field, although the exact value would depend on the field scale. Our experience is that, once the results are normalised by the value of the maximum applied vertical load, the influence of relative density on the results is quite weak, so that in fact our results would have quite a wide applicability.

\section{REFERENCES}

Bell, R. W. (1991). The analysis of offshore foundations subjected to combined loading. MSc thesis, University of Oxford.

Ngo Tran, C. L. (1996). The analysis of offshore foundations subjected to combined loading. DPhil thesis, University of Oxford. 